\title{
Gene Expression Microarrays in Microgravity Research: Toward the Identification of Major Space Genes
}

\author{
Jade Q. Clement \\ Department of Chemistry, Texas Southern University, Houston, Texas
}

USA

\section{Introduction}

Crewmembers of space flights commonly experience certain health condition changes such as immune system dysregulation, musculoskeletal changes (e.g., significant bone and muscle loss), and neurological alterations. Since the space exploration of the 1960s and 1970s, physiological changes in several organ systems due to weightlessness have been identified. Some of the adverse effects are a decline in cellular immune responses (Leach et al, 1990; Cogoli 1993; Pippia et al; 1996; Borchers et al, 2002;), cardiovascular deconditioning (Fritsch-Yelle, et al 1996), bone deterioration (Mack et al 1967; Vose et al 1974; Atkov 1992; Schneider et al, 1995; Collet et al, 1997) and muscular atrophy (Thomason and Booth 1990; Aubers et al, 2005; Trappe et al, 2009). Human exposure to microgravity has been demonstrated to be a major environmental factor during space flight (Cogoli et al 1993; Ullrich et al, 2008). Many of the adverse effects of microgravity have much in common with earthbound health problems related to low physical activity or less mechanical loading. For example, bone and muscle loss as well as immune system dysfunction are some of the main consequences common to both extended spaceflight and physical inactivity such as that associated with the aging population and people suffering from degenerative disorders. In a recent review article, mechanotransduction is attributed as the possible convergence point for all the "abnormalities" associated with aging and microgravity because human adaptation to microgravity has all the features of accelerated aging (reviewed by Vernikos \& Schneider 2010). More recently, similarities between the clinical presentation (such as atrophy in muscle and bone, cardiovascular disturbances, and alterations in renal, immune and sensory motor systems) of individuals living with spinal cord injury (SCI) and those who experience prolonged gravity unloading (especially astronauts) are reviewed (Scott et al, 2011). It is evident that continued effort in microgravity research will deeper our understanding of space adaptation response and improve many of our health-related problems on earth. Thus, microgravity based research can further our understanding of human diseases such as SCI, diabetes, osteoporosis and premature aging that are related to physical inactivity. Most effective counter measures can then be formulated to ensure safe experience in microgravity and promote healthy beings especially at the senior level.

Despite over 50 years of manned space flight, there is still much to be learned about the consequences of living in space for extended periods of time. Microgravity exposure from 
spaceflight has global effects on cells in virtually all organ systems in the body. Most cell types, ranging from bacteria to mammalian cells, are sensitive to the microgravity environment, suggesting that microgravity affects fundamental cellular activities. Studies at the cellular and molecular levels have been reported from both space flight and groundbased microgravity simulations. Ground-based gravity-simulation experiments at the cellular and molecular levels have gained much insight into the underlying molecular and cellular alterations induced by microgravity stress as well as the mechanisms of the microgravity effects (reviewed in Cogoli, 1993, 1996; Sonnenfeld \& Shearer 2002; Sonnenfeld 2005). Environmental change as drastic as sudden gravity change is likely to alter the function and transcriptional activities of groups of genes. This is because any change in the physiological activity of a cell or an organism is most likely the result of changes in certain genes' expressions. Through the 1990s a number of gene expression studies were carried out to determine microgravity effect on organisms and these studies tended to focus on a few genes at a time. It was only with the advent of high-throughput genomic technology such as microarrays that large scale genome-wide studies have been performed. For most genes (especially structural genes), gene expression in response to an environmental change is mainly controlled at the level of transcription, which provides the base for the successful development of mRNA-based high-throughput assays such as DNA microarray technology. The integrated application of biotechnologies in microgravity research with high throughput microarrays for gene expression analysis and various ground-based simulated microgravity models makes it possible for well controlled experimental studies (Hammond \& Hammond, 2001). In this chapter, I will first give a brief overview of the ground based simulated microgravity technology and microarray technology for space lifescience research. Then I will review the combined use of these biotechnologies in the study of microgravity effect on gene expression of mammalian cells with specific focus on the areas where most studies tend to focus on such as cells in the immune system, bone, and muscles. In addition, I will make an attempt toward the identification of major space genes by combing data from all the retrievable microarray-based microgravity studies for each of the specific areas as well as an overall combination of these areas with other less studied areas through bioinformatics analysis. Furthermore, I will discuss the initial list of candidate major space genes that are most frequently altered by microgravity environments through microarray based assays and cross-platform, cross-species bioinformatics analysis.

\subsection{An overview of two relevant biotechnologies in space bioscience research: Simulated microgravity and gene expression microarrays}

As we depend on the unit gravity $(1 \mathrm{~g})$ on earth for our daily lives, most of the cells in our body depend on the gravity for proper growth and function. When the cells are placed in reduced gravity environment, many of their functions are affected at various degrees. A clear understanding of microgravity effects on our genes of cells in our organ systems is essential for extraterrestrial health of space travelers. Because of the high-cost and low efficiency of space flown experiments, ground-based methods for simulating the microgravity environment have been developed. These simulated microgravity studies include head down bed rest for humans (LeBlanc et al, 2007), tail suspension for rodents (Sonnenfeld \& Shearer 2002; Sonnenfeld 2005), cell and microorganism cultures with high aspect ratio wall vessel bioreactors (RWV) (Schwarz et al, 1992; Tsao et al 1992; Hammond \& Hammond 2001; Nickerson et al, 2003) and random positioning machines (RPM) (Hoson et al 1993; Walther et 
al, 1998; Pardo et al, 2005), denervation (Nikawa et al, 2004), and diamagnetic levitation (Dai et al, 2009; Hammer et al, 2009). Bed rest with the head tilted down at $\sim 6^{\circ}$ has been found to induce physiological alterations similar to those experienced in the space environment. In a similar way, tail suspension for mice and rats presents physiological effects analogous to those observed in a microgravity environment. To date, most of the microarray based studies of microgravity effects on gene expressions have used the ground-based RWV and RPM bioreactors to simulate microgravity environment (Figure 1 \& Table 1 ). The following section in the introduction gives a brief overview of the major kinds of simulated microgravity models.

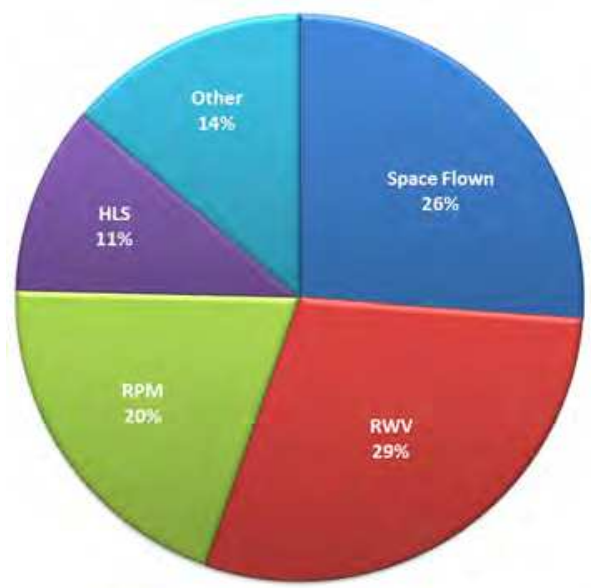

Fig. 1. The pie chart shows the percentage of each kind of microgravity used for the microarray studies discussed in this chapter.

\subsubsection{Some ground-based simulated microgravity in bioscience research}

Ground-based gravity-simulation experiments at the cellular and molecular levels have gained much insight into the underlying molecular and cellular alterations induced by microgravity stress as well as the mechanisms of the microgravity effects. In ground-based microgravity bioscience research, most simulation models simulate reduced gravity in the range of $10^{-4} \sim 10^{-6} \mathrm{~g}$ which is very small, close to "micro" (10-6) g level (Klaus 2001). The most commonly used devices for simulating a microgravity environment are the RWV (Figure 2A) and the RPM (Figure 2B), which are also known as the 3D clinostat (van Loon 2007). The RWV and RPM bioreactors were developed to simulate microgravity by mimicking a functional weightless state. The RWV bioreactor rotates cells in a zero head space suspension culture that keeps the cells in a near free fall state (Figure 2A), which we have used for our studies (Clement et al 2007; 2008). The RPM is constructed of two independently rotating frames; one inside the other (Figure 2B). The frames are computer controlled and rotated at random rates (Hoson et al, 1997). This allows samples to continuously randomly position resulting in a vector-averaged simulation of near weightlessness (van Loon, 2007). Both of these systems have been designed to attempt to mimic the weightlessness experienced by objects in orbit around the Earth. Neither system eliminates gravity, but they do make a time-averaged g-vector close to zero (Klaus 2001). Both devices do not allow the cells to receive gravitational loads in any fixed direction. 


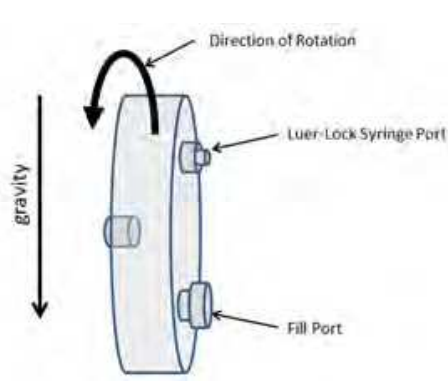

(a)

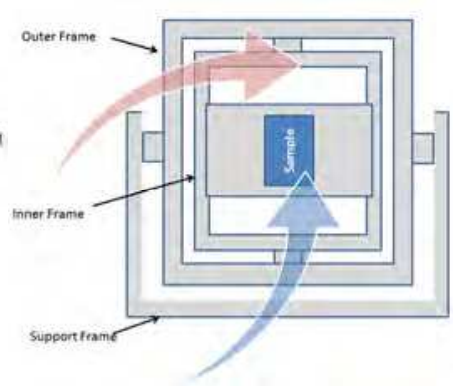

(b)

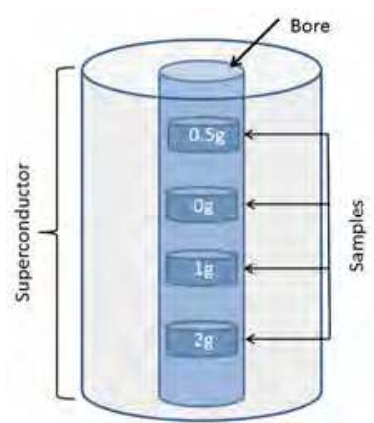

(c)

Fig. 2. A Simplified Schematic View of How the Three Ground-Based Simulated Microgravity Bioreactor Models Work. a). Rotating Wall Vessel bioreactor, rotating along horizontal axis. b) Random Positioning Machine: The blue arrow shows the direction of rotation of the outer frame and red arrows shows the rotation of the inner frame. c) Diamagnetic levitation model: A simple schematic of a variable magnetic force apparatus, a superconducting solenoid encased in a liquid nitrogen shielded liquid helium dewar with a room temperature bore passing through the center.

In addition to the RWV and RPM models, another ground-based simulated microgravity model that has been used less frequently is the diamagnetic levitation model (Figure 2C). Diamagnetic levitation is a method that uses magnetic force to create a near weightless state for ground based gravity studies. Such a variable magnetic force apparatus (VMF) is used to simulate a gravity environment from $0 \mathrm{~g}$ to $2 \mathrm{~g}$ (Valles \& Guevorkian 2002; Coleman et al, 2007; Hammer et al, 2009). The device is essentially a superconducting solenoid encased in a liquid nitrogen shielded liquid helium dewar with a room temperature bore passing through the center (Figure 2C). Samples placed in the bore experience different gravitational force depending on the vertical position in the bore (Valles \& Guevorkian 2002; Coleman et al, 2007).

\subsubsection{Genomic technology of gene expression microarrays}

Since the first microarray studies were published over 15 years ago, DNA microarrays have been used in many areas of biomedical sciences. Gene expression DNA microarrays have the potential to become key tools in space bioscience research because gene activity regulation is mostly controlled at the RNA level which is mainly determined by transcription initiation step. There are essentially four main manufacturing techniques for DNA microarrays: photolithography, contact printed, non-contact printed (inkjet), and bead arrays. Photolithography is a form of photochemical synthesis. A main advantage is the ability to put millions of features on one chip (Dalma-Weizhausz et al, 2006). Contact printing involves using robotically controlled print heads that spot or "print" the cDNA or oligonucleotides on a glass slide. Contact printed microarrays are what are commonly used for creating in-house microarrays. Non-contact printed works in a similar fashion to an inkjet printer. This technology does not have the capacity of arrays manufactured through photolithography, but it is improving every year. In 2006, around 180,000 features could be printed on one glass slide (Wolber et al, 2006). Today that has risen to close to 500,000 (Agilent website). With bead arrays the oligonucleotides are attached to $3 \mu \mathrm{m}$ silicon beads 
which are randomly deposited on a substrate such as a glass slide. The technology allows for hundreds of thousands of features to be attached to one slide (Fan et al, 2006). Both the photolithography and bead array are proprietary process of Affymetrix and Illumina, respectively. Adoption of these kinds of arrays, means adopting a complete system including the microarray scanner. In contrast, the contact and non-contact printed arrays are printed on glass microscope slides and can be used in a wide variety of microarray scanners and with a wide variety of software packages.

Although the high throughput gene expression microarray analysis is tremendously time efficient in that genes from the entire genome can be analyzed simultaneously in one experiment, there have been a number of concerns that have called into question the validity of microarray technology. With spotted (contact printed) microarrays there is evidence that cross-hybridization can happen (Handley et al, 2004), which reduces the specificity of the detection power. There have also been major concerns about the reproducibility of microarray data (Tan et al, 2003) as well as the bias and lack of interpretation that is present in many microarray studies (Richard, 2010). However, high fidelity tends to occur from experiments or studies performed using the same platform within a research laboratory. Tan et al reported a study that used the same samples and conditions, but three different microarray platforms. They found there was a high correlation $(>0.9)$ between the data using the same platform, but when the data was compared between platforms it was as low as 0.47 and only reached 0.59 at best (Tan et al, 2003). Despite the justified concerns over the repeatability of results and cross-platform correlations, microarrays still hold tremendous potential for application to research into areas involving changes in environmental conditions such as microgravity research. In recent years, the MicroArray Quality Control (MAQC) consortium has shown that if standards are met and maintained, microarrays can yield a wealth of reliable data. They were able to show that if proper standards are set and followed inter-platform and intra-platform results are reproducible (MAQC Consortium, 2006). In addition to standardization of protocols, it is important to perform biochemical assays (such as Northern blotting, RT-PCR, etc.) to validate some of the microarray data obtained in individual research labs (Clement, 2010). Most microarrays that are currently being used are high-density, whole genome and multiplexed microarrays. Regardless of microarray platforms, the general procedure for a gene expression microarray assay is more or less the same towards evaluating mRNA abundance.

Once an experimental design has been decided upon, the procedure can be divided into bench work (wet lab) and desk work (computer analysis). A more detailed discussion of gene expression microarray and experimental design can be found from recent publications (Stekel et al 2003; Clement 2010).

\subsubsection{Combined use of microarrays and simulated microgravity biotechnologies in the search for gravity sensitive genes}

With the advent of high-throughput genomic technology such as gene expression microarrays, large scale genome-wide search for gravity sensitive genes have been carried out using mRNAs from a variety of organisms such as human, rat, mouse, xenopus, yeast, C. elegans, Drosophila, and several types of plants and microorganisms. The majority (about two thirds) of these studies have been on gene expression in cells grown in some form of simulated microgravity (Table 1). 


\begin{tabular}{|c|c|c|c|c|c|c|}
\hline Organism/Cell or Tissue Type & $\begin{array}{c}\text { Type of } \\
\text { Microgravity }\end{array}$ & Duration & $\begin{array}{l}\text { Microarray } \\
\text { Patform }\end{array}$ & Vendor & Author & Year \\
\hline \multicolumn{7}{|l|}{ Human } \\
\hline Renal cortical cells & RWV/STS & $6 \mathrm{~d}$ & CDNA & Incyte & Hammond et al & 1999 \\
\hline Renal cortical cells & $\mathrm{RWV} / \mathrm{STS}$ & $6 d$ & CDNA & Incyte & Hammond et $a$ & 2000 \\
\hline HepG2 & RWV & ? & CDNA & Contech & Khacustov et al & 2001 \\
\hline Jurkat & STS & $24 \mathrm{~h}, 4 \mathrm{~h}$ & CDNA & Genefilters & Lewis et al & 2001 \\
\hline WI 38 Fibroblast & STS & $4 \mathrm{~d} 23 \mathrm{~h}$ & CDNA & in house & Semova et al & 2002 \\
\hline T-cells & B & $22 \mathrm{~h}$ & $C D N A$ & in house & Meloni et al & 2002 \\
\hline T-Cells & RPM & $4 \mathrm{~h}$ & oligonucleotide & Affymetrix & Boonyarantanakcrnkit et al & 2005 \\
\hline T-Cells & $\mathrm{RWV}$ & $24 \mathrm{~h}$ & oligonucleotide & Affymetrix & Wrd et al & 2006 \\
\hline Quadricep femoris & $B R$ & $20 d$ & cligonucleotide & AceGene & Ogawa et al & 2006 \\
\hline EA.hy926 Endothelial & RPM & $7 d, 10 d$ & multiplex array & unkown & nfangar et al & 2007 \\
\hline HepG2 & RWV & $T C 1 d, 3 d, 4 d$ & oligonucleotide & Agilent & Cement et $\mathbf{a}$ & 2007 \\
\hline NOS-1 Osteoblasts & RPM & $3 d$ & CDNA & Oontech & Yamada et al & 2007 \\
\hline HEKD01 & RWV & $\begin{array}{c}3 d, 4 d, 4 d=15 d r, \\
9 d+50 d r, 10 d+60 d r\end{array}$ & digonucleotide & Agilent & Clement et $a$ & 2008 \\
\hline Soleus \& Vastus Lateralis & $B R$ & $60 d$ & oligonucleotide & in house & Chopard et al & 2009 \\
\hline MG63 Ostecblasts & $\mathrm{DL}$ & $24 \mathrm{~h}$ & CDNA & Affymetrix & Qian et al & 2009 \\
\hline Vastus Lateralis & uus & 48h UL, 24h RL. & digonucleotide & unknown & Reich et al & 2010 \\
\hline TSCES \& WYK1 Lymphoblastoid & iss & $8 d$ & oligonucleotide & Agilent & Takahashi et al & 2010 \\
\hline Mesenchymal Stem Cells & RWV & $24 \mathrm{~h}$ & oligonucleotide & Affymetrix & Sheyn et al & 2010 \\
\hline \multicolumn{7}{|l|}{ Mouse } \\
\hline $2 T 3$ & RPM & 3d & digonucleotide & Amersham & Pardo et al & 2005 \\
\hline $2 \mathrm{~T} 3$ & RPM & $3 d$ & digonucleotide & Affymetrix & Patel et al & 2007 \\
\hline soleus \& gastrocnemius & HIS & $24 \mathrm{~h}$ & oligonucleotide & Agilent & Mazzati et al & 2008 \\
\hline Brain & HIS & $2 w k$ & CDNA & in house & Frigeri et al & 2008 \\
\hline Triceps surae & STS/HLS & $12 \mathrm{~d}$ & digonucleotide & Affymetrix & Allen et al & 2009 \\
\hline Ostecblast & RWV & sd & cligonucleotide & Agilent & Capulli et a & 2009 \\
\hline MC3T3-E1 Ostecblast & $\mathrm{DL}$ & $2 d$ & oligonucleotide & Affymetrix & Hammer et al & 2009 \\
\hline Embryonic Stem Cells & $R W V$ & $7 \mathrm{~d}$ & CDNA & Roche & Fridey et al & 2010 \\
\hline RAW 264.7 Osteoclasts & RWV & $24 \mathrm{~h}$ & oligonucleotide & Agilent & Sombandam et al & 2010 \\
\hline Thymus & STS & $13 d$ & oligonucleotide & Affymetrix & Lebsack & 2010 \\
\hline \multicolumn{7}{|l|}{ Rat } \\
\hline Soleus & HLS & $35 \mathrm{~d}$ & CDNA & Contech & Wittwer et al & 2002 \\
\hline Soleus & HLS & 21d & oligonucleotide & Affymetrix & Stein et al & 2002 \\
\hline tibialis anterior and & STS & $17 d$ & CDNA & Gontech & Taylor et al & 2002 \\
\hline $\begin{array}{l}\text { gastrocnemius } \\
\text { gastrocnemius }\end{array}$ & STS/HIS/ON & $16 \mathrm{~d}$ & oligonucleotide & Affymetrix & Nikawa et al & 2004 \\
\hline Soleus & HLS & $7 d, 7 d+1 d r, 7 d+7 d r$ & CDNA & Contech & Dapp et al & 2004 \\
\hline $\mathrm{PC}_{2}$ & RWV & $4 d$ & CDNA & in house & Kwon et al & 2006 \\
\hline BMSC & RWV & 3d & oligonucleotide & Capital Bio & Dai et al & 2007 \\
\hline \multicolumn{7}{|l|}{ Xenopus } \\
\hline A6 Kindney & RPM & $5 d, 8 d, 10 d, 15 d$ & cligonucleotide & Agilent & Kitamotoet al & 2004 \\
\hline A6 Kindney & RPM & $5 d, 8 d, 10 d, 15 d$ & digonucleotide & Agilent & Kitamotoet al & 2005 \\
\hline As Liver & RPM & $5 d, 8 d, 10 d, 15 d$ & digonucleotide & Aglent & lkuzawa et a & 2007 \\
\hline As Liver & RPM & Sd, $8 \mathrm{~d}, 10 \mathrm{~d}, 15 \mathrm{~d}$ & digonucleotide & Agilent & |kuzawa \& Asashima & 2008 \\
\hline \multicolumn{7}{|l|}{ Yeast } \\
\hline S. Cerevisiae & RWV & $20 \mathrm{~m}, 60 \mathrm{~m} 190 \mathrm{~m}$ & digonucleotide & Affymetrix & Johnson et al & 2002 \\
\hline 5. Cerevíize & RWV & $\begin{array}{l}5 \text { generations, } 25 \\
\text { generations }\end{array}$ & digonucleotide & Affymetrix & Sheehan et $a$ & 2007 \\
\hline \multicolumn{7}{|l|}{ Bacteria } \\
\hline Salmonella enterica & RWV & $10 \mathrm{~h}$ & CDNA & in house & Wilson et al & 2002 \\
\hline Solmonello enterica & RWV & $10 \mathrm{~h}$ & CDNA & in house & Wilson et al & 2002 \\
\hline Salmonello enterica & RWV & $12 \mathrm{~h}$ & CDNA & FPGRC & Chopra et al & 2006 \\
\hline Salmonello typhimurium & STS & $?$ & CDNA & inhouse & Wilson et al & 2007 \\
\hline Escherichia Coli & RWV & 10 generations & CDNA & Sigma-Genosys & Tucker et $a$ & 2007 \\
\hline Rhodosp irittum rubrun & SF & $10 \mathrm{~d}$ & oligonucleotide & in house & Mastroleo et al & 2009 \\
\hline Pseudomonas aeruginosa & RWV/RPM & $24 \mathrm{~h}$ & oligonucleotide & Affymetrix & Crabbe et al & 2010 \\
\hline \multicolumn{7}{|l|}{ Plant } \\
\hline Arabidopsis Thatia & RPM & $?$ & CDNA & in house & Kittang et al & 2004 \\
\hline Arabidopsis Thatia & RPM/SR & $6 \mathrm{~m}$ & CONA & inhouse & Martzivanou et $a$ & 2006 \\
\hline Ceratopteris richardii (Fern) & STS & ? & CDNA & in house & Salmi \& Roux & 2008 \\
\hline Hordeum vulgare (barley) & iss & $?$ & oligonucleotide & unknown & Shagimardanova et al (Russian) & 2011 \\
\hline \multicolumn{7}{|l|}{ Drosophila/C.Elegans } \\
\hline C.elegans & SF & & CDNA & Affymetrix & Hagashibata et al & 2006 \\
\hline C.elegans & iss & $10 d$ & oligonucleotide & Affymetrix & Selch et al & 2008 \\
\hline Drosophilo melanogaster & ISS/RPM & 3.5d & oligonucleotide & Affymetrix & Herranz et al & 2010 \\
\hline Drosophilo melanogaster & STS & $12 \mathrm{~d}, 18.5 \mathrm{hh}$ & oligonucleotide & Affymetrix & Marcu et al & 2011 \\
\hline \multicolumn{2}{|l|}{ ISS = International Space Station } & \multicolumn{5}{|l|}{$B R=$ Bed Rest } \\
\hline \multicolumn{2}{|l|}{ STS = Space Shuttle } & $D=$ Denervation & & & & \\
\hline RWV $=$ Rotating Wall Vessel Bioreactor & & $B=$ Balloon & & & & \\
\hline RPM $=$ Random Positioning Machine & & UuS $=$ Unilateral L & sion & & & \\
\hline HLS = Hind Limb Suspension & & $S R=$ Sounding Rocket & & & & \\
\hline
\end{tabular}

Table 1. Publications on Microarray Based Analysis of Microgravity Effects on Cells and Organisms 
To create the table of published microarray based microgravity studies, I started by doing two searches in PubMed using the search terms "microgravity and microarray" and "spaceflown and microarray". This yielded 47 and 36 citations respectively. I then analyzed the lists to remove redundancies, review articles, and articles that did not directly relate to analyzing the microgravity environment. This yielded a list of 49 published articles. After reviewing the literature, I was able to identify 7 more published microarray studies that did not appear in the PubMed searches. I added these to create the final list of 56 microarray based microgravity studies. Microarray data from these microgravity studies will be subjected to bioinformatics analysis towards the identification of major space genes.

The main aim of this chapter is therefore to review the current status of gene expression microarray technology in space bioscience research.

\section{Microarray analysis of microgravity exposed cells of the immune system}

The complex immune system evolved on earth has many windows of opportunity for a sudden switch to the space environment to dysregulate it. Hopefully, with dedicated research efforts of the space life sciences, especially with the application of advanced biotechnologies, a better understanding of immunology in the space environment will lead to effective countermeasures.

Study of the immune system is very important since it is known that astronauts have a much higher rate of infection during and after spaceflight (Sonnenfeld 1988; Sonnefeld 2005; Klaus and Howard 2006). It has been shown that inhibition of $\mathrm{T}$ cell activation in microgravity was a result of microgravity itself; factors other than microgravity can be excluded from the depressed activation of lymphocytes during spaceflight (Cogoli et al 1983; Ullrich et al, 2008). To understand the molecular mechanisms for the reduced activation of $\mathrm{T}$ cells during microgravity, many experiments have been documented from various laboratories using a variety of cell lines or animal models exposed to spaceflight and different simulated microgravity models (reviewed by Cogoli 1997; Sonnefeld 2005; Aponte et al, 2006). Although variable and contradictory results are common, overall evidence indicates that many functions such as signal transduction, cell-cell contact, cytoskeleton, and cell migration tend to be altered in microgravity. Experiments with human and mouse lymphocytes demonstrated a significant decrease in cell proliferation and in IL-2 and IL-Ra synthesis (Cogoli, 1997; Walther et al, 1998). An increase in urinary IL-6 excretion was observed on space flight and after landing (Stein and Schluter, 1994). IL-2 production decreased after space flight for three different $\mathrm{T}$ cell subsets $\left(\mathrm{CD} 3^{+}, \mathrm{CD} 4^{+}\right.$ and $\mathrm{CD}^{+}$) and IFN- $\gamma$ production decreased in the $\mathrm{CD}^{+}$subset (Crucian et al, 2000). Spaceflight studies performed with rodents have found that microgravity caused rodents to be more susceptible to infection (Sonnenfeld et al, 1988), inhibited NK cell activity (Rykova et al, 1992), reduced capability for wound healing (Davidson et al., 1999), inhibited INF-Y production (Gould et al., 1987) and a reduction in lymphoid organ size (Congdon et al, 1996). A study using rhesus monkeys, microgravity inhibited IL-1 production and decreased response to colony stimulating factor (CSF) on bone marrow cells (Sonnenfeld et al, 1996). Similar to the in flight experiments, antiorthostatic suspension experiments on rodents have shown a increased levels of corticosterone, a reduced ability to clear bacteria from organs and a increased rate of mortality (Aviles et al, 2003). The important function of cytoskeleton in sensing of microgravity during spaceflight is reviewed (Hughes- 
Fulford, 2003). Over the past three decades, many more (thousands) publications have documented various results toward elucidation of microgravity mediated immune dysfunction. The most consistently observed effects of microgravity on the immune system have been a reduction in T cell and NK cell populations and functions, especially a reduction in cell-mediated immunity, altered cytokine production, as well as an increased susceptibility to infection under space flight conditions. Decreases in the reactivity of T cells, $\mathrm{T}$ cell cytotoxicity, and $\mathrm{T}$ cell helper activities have been documented for both spaceflight and ground based simulated microgravity studies.

Towards deciphering why T-cell activation is inhibited in microgravity, genome-wide microarray based analysis has become increasingly used within the last decade. Cell response to microgravity has been studied in relatively well-controlled clinostats and bioreactor cell cultures which are particularly convenient for time-course or multiplexed microarray analysis. The first report on cDNA microarray analysis of space flown $\mathrm{T}$ cells was documented in 2001(Lewis et al, 2001). In this study, human T cells (Jurkat, human acute leukemic T cell line, E6-1) were space-flown for $24 \mathrm{~h}$ and $48 \mathrm{~h}$. cDNA microarray (GeneFilter ${ }^{\mathrm{TM}}$ ) analysis was performed to evaluate gene expression of 4,324 human genes at the $24 \mathrm{~h}$ time point and 20,000 genes at the $48 \mathrm{~h}$ time point. They identified differentially expressed genes that encode proteins for cytoskeletal organization, growth and metabolism, adhesion and signal transduction, transcription, apoptosis and tumor suppression (Lewis et al, 2001). The cDNA microarray (GeneFilterTM) analysis of Jurkat cells flown on STS-95 in 1998 found that around $98 \%$ the genes examined had similar expression patterns when the space-flown cells were compared to ground control cells. They were the first to report that cytoskeletal genes were differentially regulated: calponin, dynamin, tropomodulin, keratin8, myosins, ankyrin, an actinlike protein, plectin, and C-NAP-1 were upregulated; gelsolin was downregulated. Their data indicated that the expression of genes functioning in interconnect cytoskeletal elements to each other and to cell membrane, regulate filament polymerization and microtubule organization centers were altered by spaceflight (Lewis et al, 2001).

Another earlier microarray based analysis of microgravity effects on $\mathrm{T}$ cell activation was reported by Meloni et al (2002). They intended to discriminate between effects of microgravity and cosmic radiations on the influence of microgravity on mitogenic activation of $\mathrm{T}$ cells and studied the effects of high cosmic radiations on the gene expression in human $\mathrm{T}$ cells boarded in a stratospheric balloon (22 hours flight). They used cDNA microarray hybridization technology for the gene expression analysis and found that activated cells react to the ionizing stress by activating genes involved in cell cycle check-point, oxidative stress response, heat shock protein production or by repressing genes involved in antigen recognition.

Aiming to examine the roles of early genes in initiating and maintaining $\mathrm{T}$ cell activity, Hughes-Fulford's lab performed a microarray analysis of simulated microgravity (4h RPM) effect on human peripheral lymphocytes and found that PKA was a key player in the loss of T cell activation in microgravity (Boonyaratanakornkit, et al. 2005). For this study they used Human Genome Focus Arrays (Affymetrix) and identified 91 down-regulated genes as a result of exposure to simulated microgravity. The expression of early genes regulated primarily by transcription factors NF- $\kappa \mathrm{B}, \mathrm{CREB}, \mathrm{ELK}, \mathrm{AP}-1$, and STAT were impaired in microgravity, suggesting that microgravity either slows, impedes, or fully blocks key 
signaling pathways in early T cell activation (Boonyaratanakornkit et al, 2005). They showed that IL-2 was among the down-regulated genes, which correlates well with previous nonarray based reports (Cogoli et al, 1993; Pippia et al, 1996; Walther et al, 1998; HughesFulford et al, 2005). Interestingly, IL-2 was also significantly decreased (and IL-10 expression was increased) in a recent real time PCR based analysis of gene expression in T-cells of mice after being flown in space aboard STS-118 for 13 days (Gridley et al, 2009).

Ward et al used Affymetrix Human U133A arrays to study activated human peripheral lymphocytes exposed to simulated microgravity in RWV (22 rpm) for 24h (Ward et al, 2006). From their triplicate experiments they identified 89 (10 up, 79 down) genes that were statistically significant $(\mathrm{P} \leq 0.01)$ and at least 1.5 fold up or down-regulated in an all of the arrays. A larger proportion of these affected genes are found to be players in fundamental cellular processes such as immune responses, signal transduction, DNA repair and apoptosis, and metabolic pathways (Ward et al, 2006).

A microarray based study of mRNA expression in murine thymus tissue extracted from C57BL/6NTac female mice that had been flown aboard the space shuttle Endeavour (STS118) for thirteen days was reported recently by Lebsack et al (2010). They used Affymetrix gene chips for this study and found 970 genes significantly differentially regulated (644 up and 326 down). Among the identified genes in stress response, RNA binding motif $3(\mathrm{RBM} 3)$ and cold inducible binding protein (CIRBP) were up regulated, while HSP90, HSP110, STIp1, FKBP4 were down regulated. More importantly, genes that regulate immune response were affected by space flight: CD44 and CXCL10 that promote T cell development were down regulated; whereas CTLA-4 (negative regulator of $\mathrm{T}$ cell activation) mRNA was upregulated. Overall, the genes identified in this study were involved in stress regulation, glucocorticoid receptor metabolism, and $\mathrm{T}$ cell signaling and activity (Lebsack et al, 2010).

The above five studies made good use of the biotechnologies in their respective microgravity studies. Although impressive findings are documented in each individual report, widely varied results in terms of the type of genes or trends in expressions are noted among these microgravity studies using microarrays in the immune system. For a systematic view of these studies, I attempted to compile the data into a tabulated form and was hampered by obstacles, mainly due to a lack of overlap in the identified gravity sensitive genes. The only "overlap" was two genes (STAT1 and XCL1) found to be differentially regulated in two studies: in one study they were both down-regulated (Boonyarantankornkit et al, 2005), while in the other they were both up-regulated (Ward et al, 2006). The large variation in the resulting gravity sensitive genes may in part be due to numerous variables and the overall complexity of the immune system itself (Gridley et al, 2003). In addition, variations of the types of microgravity, different cell lines or cell types, various microarray platforms, etc., could also contribute to the differences in the results. Furthermore, how the data was documented and reported can also contribute to the lack of consistency in resulting sensitive genes. Another contributing factor is the fact that these few studies span a large time frame $(2001 \sim 2010)$ for the relatively young microarray biotechnology, the time period the technology itself undergoes development and is still in the process of standardization. With more standardization in the genome wide assays, meaningful compilation of data can be applied efficiently in a statistical analysis toward the identification of major space genes. 
Nonetheless, it is still of interest to see which pathways or molecular functions the gravity sensitive genes from afore mentioned studies. To generate the KEGG Pathways for immune system related cells, I needed to prepare the data for analysis in DAVID (Database for Annotation, Visualization, and Integrated Discovery)(Huang et al, 2009a; Huang et al, 2009b). Out of the five microarray studies, four had gene tables, or lists of genes that were relatively easy to use. Three of these lists used human cells (Lewis et al, 2001; Boonyarantankornkit et al, 2005; Ward et al, 2006), one used mouse tissue (Lebsack et al, 2010). Since the majority of the studies were done with human cells, I chose those three gene lists to compile a master gene list by manually combining the genes from the three microarray studies and using the DAVID conversion tool to convert them all into the same format. This conversion is necessary because of inconsistency in the way gene tables are presented: some of the gene lists included gene bank accession numbers and gene symbols, some included gene symbols but no accession numbers, and others included accession numbers but no symbols, still others with no gene list at all. To limit confusion and for ease of references, both accession numbers and gene symbols should be included in gene lists whenever possible. The converted gene list resulted in 142 genes after redundant, unknown, or unable to define genes were eliminated. This combined gene list was uploaded to the DAVID Functional Annotation tool to identify the statistically significant KEGG Pathways (Table 2). Interestingly but not surprisingly, most of the functional pathways identified using the combined gravity sensitive genes are key pathways for innate and adaptive immunity (Table 2). This is indeed significant, despite the fact that such a large variation in the type and trends of gene expressions were found among these studies.

\begin{tabular}{|c|c|c|c|}
\hline Term & Count & PValue & Genes \\
\hline hsa04060:Cytokine-cytokine receptor interaction & 14 & $4 \quad 4.27 E-06$ & $\begin{array}{l}\text { CSSF2, CCL3, IL2RA, TNFSF14, CCL4, CXCL10, IIF, } \\
\text { TNFFSF9, TNFSF20, CCI20, IFNG, XCL1, XCL2, LTA }\end{array}$ \\
\hline hsa03050:Proteasome & 7 & $7 \quad 1.14 \mathrm{E}-05$ & $\begin{array}{l}5 \text { PSMBS, PSMB10, PSMC4, PSME2, PSMA3, IFNG, } \\
\text { PSMB9 }\end{array}$ \\
\hline hsa04062: Chemokine signaling pathway & 9 & 90.001014 & $\begin{array}{l}4 \text { CCI3, DOCK2, CCI120, NFKB1, XCL1, STAT1, XCL2, } \\
\text { CCL4, CXCL10 }\end{array}$ \\
\hline hsa04612:Antigen processing and presentation & 5 & $5 \quad 0.01353$ & 3 PSME2, CREB1, HSPA1A, KIR2OL3, LTA \\
\hline hsa04620:Toll-fike receptor signaling pathway & 5 & $5 \quad 0.02593$ & 3 COI3, NFKB1, STAT1, CCL4, CXCL10 \\
\hline hsa04640:Hematopoietic cell lineage & 4 & 40.071181 & 1 CSF2, IL2RA, CD59, CD2 \\
\hline hsa00970:Aminoacyl-tRNA biosynthesis & 3 & 30.076664 & 4 WARS, SARS, GAFS \\
\hline hsa04630:Jak-STAT signaling pathway & 5 & $5 \quad 0.094726$ & 6 LIF, CSF2, IL2RA, IFNG, STAT1 \\
\hline
\end{tabular}

Table 2. Pathway Identification of Microarray Identified Gravity Sensitive Genes in Immune System. Legend: red means up regulated; green means downregulated; purple means opposite trends between studies; underlined means it appears in more than one study.

Does the cell use "many roads lead to Rome" approach to adapt to microgravity environment? It may be possible that major space pathways rather than specific major space genes are key determinants for adaptation to microgravity. More studies would be needed for statistically based cross-laboratory and cross-platform analysis of microarray based data, which will provide key insight into the molecular mechanism of microgravity mediated immune dysfunction. An altered immune response to microgravity is attributed to be a key factor for bone loss because the altered production and action of cytokines in the immune system could affect bone remolding (Zayzafoon et al, 2005). 


\section{Microarray analysis of microgravity exposed bone cells}

Physical inactivity or mechanical unloading to the skeletal system is an underlying cause for bone density loss in clinical disorders such as spinal cord injury, stroke, prolonged bed-rest, aging and osteoporosis as well as in spaceflight microgravity environments (LeBlanc et al, 2005; Beller et al, 2011). Therefore, continued effort in deciphering the mechanism and finding a remedy for bone density loss is beneficial to human health both in space and on earth. Spaceflight caused bone density reduction specifically involves weight-bearing bones (Mack et al, 1967; Vose et al, 1974; Schneider et al, 1995; Collet et al, 1997; Lang et al, 2006; Keyak et al., 2009). In the space environment, bone density in the lower extremities and spine of crew member is lost at a rate of $1 \%$ to $2 \%$ per month (LeBlanc et al, 2007; Amin, 2010). Microgravity disturbs the balance between bone formation and resorption in bone remolding process: it tends to increase bone resorption functions of osteoclast and decrease bone formation functions of osteoblast. A net loss of calcium in-flight of similar magnitude to that observed in earlier studies from Skylab as well as an increase in bone resorption markers (Smith et al, 2005). Studies of spaceflights showed decreased serum levels of bone formation markers such as alkaline phosphatase (ALP), osteocalcin (OCN), and the C-terminal peptide of pro-collagen I (Collet et al, 1997; Caillot-Augusseau et al, 2000). Increased resorption with little change in formation is the main finding in space flight caused uncoupled bone remodeling (reviewed by LeBlanc et al, 2005). The unbalanced bone resorption and formation resulted in increased $\mathrm{Ca}^{2+}$ secretion. Ground-based simulated microgravity studies showed decreased bone formation (Nakamura et al, 2003; Zayzafoon et al, 2004; Pardo et al, 2005; Patel et al, 2007; 2009). Although a gene-specific approach has identified several key genes involved in bone cell growth and development that are affected in microgravity, a comprehensive genome-wide search allows for the identification of more genes as well as possible pathways through which the bone loss occurs.

A number of microarray based analysis of microgravity effect on bone cells have been published relatively recently. Pardo et al showed that gene expression of 140 genes (88 down and $52 \mathrm{up}$ ) were significantly altered after exposure of 2T3 murine preosteoblast to 3 days simulated microgravity in RPM (Pardo et al, 2005). They used CodeLink Uniset Mouse 1 Bioarrays (Amersham Biosciences) and the median intensity of all the probes to normalize the intensity of the individual probes. In agreement with spaceflight data and simulated microgravity studies, their microarray data showed genes important for bone density such as alkaline phosphatase (ALP), runt-related transcription factor 2 (Runx2), osteomodulin, parathyroid hormone-related protein(PTHrP), parathyroid receptor 1 (PthR1), and platelet derived growth factor (PDGF) were significantly down-regulated. In contrast, cathepsin $\mathrm{K}$ (responsible for bone resorption in osteoclasts) is upregulated in the 2T3 cells in response to simulated microgravity. ALP is a known marker for bone formation, and Runx2 is involved in osteoblastic differentiation and skeletal morphogenesis. Both interact with secreted bone morphogenic proteins and with insulin like growth factor 1 (IGF1), which has been shown to regulate Runx2 in endothelial cells (Qiao et al 2004). In their data, IGF1 was shown to be slightly down-regulated although it did not pass the significance test (Pardo et al 2005). PthR1 promotes the release of $\mathrm{Ca}^{2+}$ and it has already been shown to be gravity sensitive in bone cells (Torday 2003). Overall, this study shed much light on the mechanism of microgravity mediated bone loss through the use of microarray analysis. Patel et al (2007), the same research group as the 
aforementioned study by Pardo et al, published a further study on 2T3 murine preosteoblast cells grown in RWV for 3 days. The cells were seeded on microcarrier beads and rotated on the RWV at $22 \mathrm{rpm}$. Microarray analysis of the simulated microgravity treated preosteoblasts showed that the microgravity downregulated 61 and upregulated 45 genes by more than twofold compared to static $1 \mathrm{~g}$ controls. Comparison of the $\mathrm{RWV} /$ microarray data with the data from previous RPM/microarray analysis they found 14 mechanosensitive genes that were changed in the same direction. Once again ALP, runx2, PthR1, and PDGF were shown to be significantly down-regulated. Thus, the two different simulators of microgravity on the same cell line assayed by microarray kits from two different vendors produce similar results with regard to bone cell differentiation and osteoblast function. In a further non-microarray based study (Patel et al, 2009), they cultured 2T3 cells in SMG using RPM and PCR-based analysis. They again found that ALP, Runx2, PthR1 were down-regulated in simulated microgravity. They also found that low magnitude and high frequency (LMHF) mechanical loading $(0.1 \sim 0.4 \mathrm{~g}$ at $30 \mathrm{~Hz}$ for $10 \sim 60 \mathrm{~min} /$ day) prevented a decrease in ALP, Runx2, PthR1, but static conditions had no effect (Patel et al, 2009).

Yamada et al studied osteoblasts (NOS-1 cells derived from a human osteosarcoma) that were exposed to 3 days of simulated microgravity in RPM. They used Atlas ${ }^{\mathrm{TM}}$ Human 3.8K microarray for the mRNA analysis. As with the previous studies, ALP activity was significantly reduced in the cells exposed to simulated microgravity. However, there is not a gene list for the microarray analysis. It is significant to find that the addition of chitosan (a natural polyaminosaccharide) significantly increased ALP activity in the cells exposed to simulated microgravity (Yamada et al 2007).

A recent study by Capulli et al (2009) used primary mouse calvarial osteoblasts grown in simulated microgravity (RWV) for 5 days and used Agilent microarrays for the analysis of simulated microgravity exposed bone cells. The cells were seeded to microcarrier beads and grown in RWV at $16 \mathrm{rpm}$ to simulate microgravity. They found that 133 genes were differentially regulated, 45 genes were significantly up-regulated and 88 were downregulated. The significantly differentially regulated genes were presented in tables of clusters and molecular function classifications. Among the differentially regulated genes are genes involved in osteoblast differentiation, function, and osteoblast-osteoclast cross-talk, genes of extracellular matrix, glycosaminoglycan/heparin-binding activity, and growth factor activity. The findings concerning FN1 are consistent with other studies in different cell lines (Dapp et al, 2004, Nikawa et al, 2004, Sheyn et al, 2010). The finding with CTGF is also consistent with other findings (Sheyn et al, 2010).

Qian et al (2009) examined gene expression profile changes of human osteoblast-like cell line MG-63 in response to $24 \mathrm{~h}$ simulated microgravity, highmagneto-gravitational environment (HMGE). They used $35 \mathrm{~mm}$ cell culture plates seeded with cells and placed them into the HMGE at special positions to achieve the gravity effects of 0,1 , and $2 \mathrm{~g}$ by the object stage. They used a self-made circulating water-bath as a control for temperature of $37 \pm 0.5^{\circ} \mathrm{C}$. High-density human genome (HG) U133 Plus 2.0 Arrays (Affymetrix) were used for the gene expression analysis. Among the total of 54,613 gene probes examined with the microarray, they found 53 genes were statistically down-regulated and 55 genes were statistically up-regulated compared with the $0 \mathrm{~g}$ with the temperature control. They presented the identified genes in tables according to cellular functions. They specifically 
noted that cytoskeleton-related genes such as WASF2 and WIPF1 genes were the most mechanosensitive.

Hammer et al used diamagnetic levitation to conduct experiments of how gravity affects MC3T3-E1 osteoblastic cell line. In the experiment, they exposed cells to $0 \mathrm{~g}$, $1 \mathrm{~g}$, and $2 \mathrm{~g}$ gravity. The cells were exposed to the magnetic field for two days after which RNA was extracted and microarrays were run. They used Affymetrix Mouse genome arrays and the intensity of housekeeping genes for normalization, Robust Multichip Average (RMA) for normalization. The data was then scaled to a median of 100; genes below 50 were filtered out. They used a 3 fold cut-off to determine the gene list for further bioinformatics analysis. Based on this criterion they identified 2270 genes that were upregulated and 135 genes that were down-regulated when $1 \mathrm{~g}$ samples were compared to $0 \mathrm{~g}$ samples. The focus of the paper is more on testing the diamagnetic levitation biotechnology rather than on the genes that are differentially regulated (Hammer et al, 2009). .

Sambandam et al (2010) published a recent study of osteoclast grown in RWV SMG (16 rpm to simulate $0.0008 \mathrm{~g}$ environment) for 24 hours. For the study they used Agilent whole genome arrays. They followed standard statistical procedures to identify their list of differentially regulated genes. They identified 3,404 differentially expressed genes. They have followed MIAME standards by depositing the microarray profile data in the GEO database. Some genes of interest that were up-regulated include CTSK, CTSL, and CTSB, as well as several MMPs, bone matrix degrading proteases. Their microarray data agrees with previous finding that stimulation of osteoclastogenesis in microgravity environment.

All seven studies also made good use of the biotechnologies in their respective studies. To further examine all the microarray-identified genes from bone cells exposed to microgravity, I performed pathway analysis using DAVID. As in the immune system section, the use of gene bank accession numbers and gene symbols are not standardized here also. In order to find out which pathways the altered genes are involved, I first used the DAVID conversion tool to convert them all into the same format. Out of the seven microarray studies involving bone cells, five studies have the gene lists published in the paper or supplemental tables. Since the majority (four out of five) were studies done in mice (Pardo et al, 2005; Patel et al, 2007; Capulli et al, 2009; Sambandam et al 2010) and one was in human (Qian et al, 2007), I chose to use those four gene lists to compile into one master list in the same format, and uploaded them to the DAVID Functional Annotation tool for pathway analysis. The list was run as species Mouse and Identified the statistically significant KEGG Pathways (data not shown).

Within the seven microarray analysis of microgravity exposed bone cells discussed above, there are certain consistency or overlap in the identified gravity sensitive genes among these different studies. Are there potential major space genes or bone-specific space genes among these studies? To this end, I performed further cross-laboratory, cross-species, crossmicrogravity-platform, and cross-microarray-platform comparative analysis here. In order to identify the major gravity sensitive genes from these microarray/microgravity studies, I manually examined and picked out the genes that appeared to be significant in more than one of the five studies (two out of the seven studies do not have a gene list with the publications nor available in supplement). Essentially, any gene that was identified in two or more of the five studies were compiled into a table along with the data values (fold changes) from each specific source of origin for direct comparison (Table 3). 


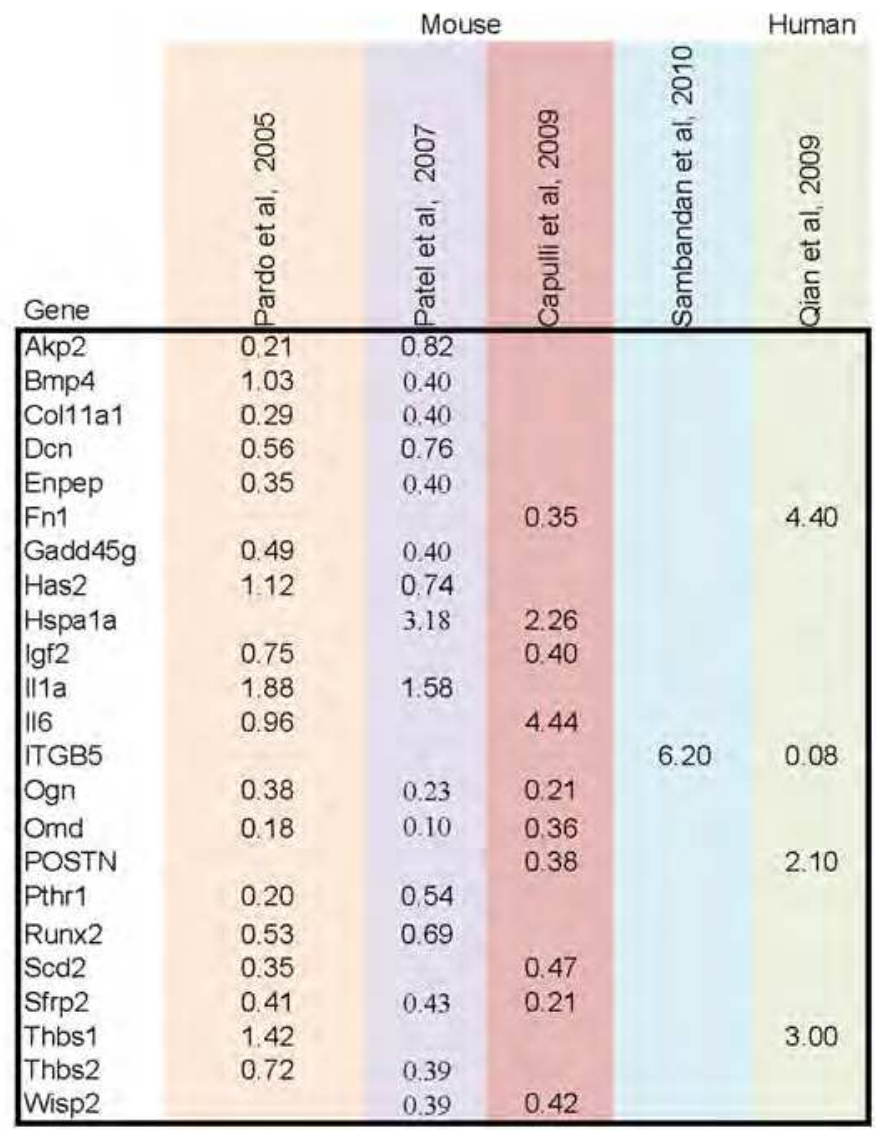

Table 3. Microgravity Sensitive Genes Identified by Microarray analysis of Bone Cells It is more apparent now with this table that the data from the same research group tends to be more consistent (compare Pardo et al 2005 and Patel et al 2007). The highest overlapped (in three of the five studies) genes were osteoglycin(OGN), osteomodulin (OMD), and secreted Frizzle-Related Protein 2 (SFRP2) and all three genes were down-regulated in all the microarray/microgravity studies that identified them (Pardo et al, 2005; Patel et al, 2007; Capulli et al, 2009). Osteoglycin(OGN) encodes a protein (a small proteoglycan) which induces bone formation in conjunction with transforming growth factor beta. Osteomodulin (OMD) is implicated in biomineralization processes. In addition to the reduction of expression of the two genes important in bone formation, the majority of the gravity sensitive genes shown in Table 3 are genes encode proteins in pathways involving ECMreceptor interaction and focal adhesion: Integrin $\beta 5$ (ITGB5), thrombospondins (THBS1, THBS2), collagen (COL11A1), and fibronectin (FN1). In addition, four components in the TGF- $\beta$ signaling pathway were also found in this table: bone morphogenic protein (BMP4), decorin (DCN), and the thrombospondins (THBS1, THBS2). Furthermore, the two cytokines, interleukin-1(IL-1) and interleukin-6(IL-6), that coordinate and regulate many cellular activities of the innate immunity were among the more frequently identified microgravity sensitive genes in bone (Table 3). 


\section{Microarray analysis of microgravity exposed muscle cells}

Muscle atrophy as a result of spaceflight has been a condition that was identified early on in the space program. As with bone cells and cells in the immune system, spaceflight also has a major effect on muscle cells. A study of an exercise program showed that crewmembers while aboard the International Space Station (ISS) for 6 months calf muscle volume and peak power decreased significantly, and there was a redistribution among the faster phenotypes, despite the fact that the crewmembers exercised regularly (Trappe et al, 2009). Microgravity effect on muscle has been one of the most studied areas in space life science research. Ground based analogs such as bed rest or unilateral leg suspension (ULLS) have been used in humans and HLS has been used in rats. Bed rest and ULLS have shown results that seem to be similar to spaceflight (Narici \& deBoer, 2011). However, it has been cautioned that the HLS using rodent models may not be the best choice when extrapolating results to humans; the processes involved in muscle atrophy and disuse in rodent and humans are very different (Rennie et al, 2010). Currently, little is even known about mechanisms of muscle atrophy and disuse in general (Rennie et al, 2010). In studying microgravity effect on muscle cells, most commonly used model systems are rodents and space flight experiments have been performed extensively using both mice and rats flown in space. The most commonly used ground based simulated microgravity models are hind limb-suspension of rodents. These have been combined with microarray biotechnology for genome wide gene expression analysis of the microgravity effect. Here I will focus my discussion on the microarray based studies and apply DAVID bioinformatics tools to examine the genes that have been identified in these studies.

Taylor et al (2002) used Clontech Atlas DNA expression array to study the alteration of gene expression profiles in skeletal muscles (tibialis anterior and gastrocnemius) of male rats flown on the STS 90 Neurolab for 17 days. They found that 50 genes showed differential regulation: 38 genes were downregulated and 12 were upregulated. Genes related to cell proliferation and growth factor cascades (such as p21 cip1, Rb, cyclins G1/S, -E, - $D_{3}$, MAP kinase $3, \mathrm{MDA}_{3}$, and ras related protein $\mathrm{RAB}_{2}$ ) were down-regulated during spaceflight. The microarray data indicates that genes involved in regulation of muscle satellite cell replication are down regulated by microgravity (Taylor et al 2002). Thus, this experiment gives further insight into the mechanisms underlying muscle atrophy and diminished muscle repair capability associated with the space environment.

Another 2002 study (Wittwer et al 2002) using Clontech Atlas 1.2K Rat arrays identified 105 genes out of 1200 tested that were significantly differentially regulated after 35 days hindlimb suspension. Much of their microarray data agreed with similar studies reported previously. Data suggested a coordinated increase in the expression of genes (PFKM, ALDOA, and GAPDH) in the glycolic pathway involved in the cytoplasmic conversion of glucose to pyruvate in 35-day HS $m$. solei. In addition, the mRNA of an enzyme that controls glycolytic flux, adenylate kinase 1 (AK1), was also increased. mRNA of proteins (LDL receptor, SR-BI, FATP, and H-FABP) involved in the uptake and transport of fatty acids from the blood into the muscle fibers decreased. mRNAs of vesicle transport proteins (IRAP, M6P/IGFR2, and VAMP3) involving mitrochondrial energy conversion were increased. These genes have been implicated in glucose uptake, mediated by the major insulinmediated glucose transporter of skeletal muscle, glut-4. Data suggests the decreased fatty acid import proteins as a regulation towards reduced fatty acid uptake and transport 
concomitant with adaptation toward greater glycogen utilization and a generally reduced energy demand in the atrophied muscle. The gene activities for intracellular protein degradation such as lysosomal protease mRNAs (cathepsin C, L, and D) and some enzymes involved in cytosolic protein degradation by proteasomes (i.e., TPPII, UBE2B, rP28 alpha, and carboxypeptidase D) were increased. Extracellular proteases (MMP-2, u-PA) as well as protease inhibitors (TIMP-2 and -3) were also increased at mRNA level. The findings gave much insight towards the understanding of skeletal muscle atrophy.

Stein et al (2002) studied soleus muscle isolated from 5 control and 5 hindlimb suspended rats (21 days) with the Affymetrix microarray system for assessing gene expression on fuel pathways within the muscle. Similar to the Wittwer et al report, they observed a consistent decrease in expression of genes involved in fatty acid oxidation and an increase in expression of genes in the glycolytic activity in the suspended group. Their microarray data further confirms that disuse atrophy is associated with a change in mRNA levels of enzymes involved in energy metabolism, a shift away from use of fat to use of glucose.

Dapp et al (2004) applied the mouse hindlimb suspension (HS) model for gene expressional alterations underlying loaddependent muscular adaptations. Gene expression was assessed from total RNA by a muscle-specific low-density cDNA microarray (custom designed Atlas cDNA arrays with 222 double spots on each nylon array). Immediate early genes such as FRA1, JUND, and JUN were induced as were IGFs, while myosin heavy chain was reduced in mouse soleus muscle after 7 days hind-limb suspension.

Nikawa et al (2004) published a study comparing gene expression patterns in gastrocnemius muscle (the largest muscle of the calf of the leg that acts by extending the foot and bending the knee) cells from rats flown in space, rats exposed to hind-limb suspension, and denervated rats. Using Affymetrix Rat Genome U34 GeneChips, they found that most gene expression changes were unique to spaceflight (Nikawa et al 2004). The DNA microarray data indicated that spaceflight specifically caused altered expression of some mitochondrial genes and cytosleletal genes (such as A-kinase anchoring protein and cytoplasmic dynein) as well as up-regulated ubiquitin ligase genes (MuRF-1, Cbl-b, and Siah-1A ). Several oxidative stress-inducible genes were also upregulated and hightly expressed in the muscle of the spaceflown rats (Nikawa et al 2004). They proposed that mitochondrial dislocation during spaceflight may have caused atrophy in the form of insufficient energy supply and leakage of reactive oxygen species from the mitochondria. Although only a fraction of the genes are discussed in limited space of the original publication, comprehensive tables of microarray data are presented in the paper, which provides a very valuable source of reference information. The same research group published another research paper using human 20 day bed rest to study muscle disuse atrophy mechanism and used DNA microarray for their genome wide gene expression analysis (Ogawa et al, 2006). Their data suggested that Cbl-b or atrogin-1 mediated ubiquitination pathway could be important in unloading induced muscle atrophy in humans.

Mazzatti et al 2008 reported a study using gene arrays (Agilent Mouse Oligo Arrays) to determine the acute effects of short-term HLS on metabolic consequences of unloading. They used Agilent whole-genome arrays to examine mRNA expression in mouse soleus and gastronemius muscle cells after 24 hours hind-limb suspension and identified 600 genes with a FDR of 0.05 and at least 1.5 fold differential regulation in both cell types. Several proteins (PPAR8, UCP-3, AMPK, and CPT1/2) that have putative roles in the maintenance 
of metabolic flexibility were upregulated. They also concluded that there was increased reliance on glucose as an energy source or a loss of metabolic flexibility. Muscle unloading appears to result in reduced fatty acid oxidation, decreased transcription of genes involved in lipid metabolism and increased expression of genes involved in glycogen synthesis (Mazzatti et al 2008). The findings that increased reliance on glucose fit with previous studies that have shown that atrophied muscle rely more on glucose for energy (Fitts et al, 2000; Henriksen and Tishler 1988; Stein et al, 2002; Martin et al, 1988).

A more recent study (Allen et al 2009) of murine skeletal muscles(gastrocnemius from mice) compared space flown mice (11-day, 19-h on STS-108 shuttle flight) with the ground-based unloading model of hindlimb suspension (one group of pure suspension and one of suspension followed by $3.5 \mathrm{~h}$ of reloading). They found that spaceflight causes differential regulation in genes involved in muscle growth and fiber type. Their microarray data showed that 272 mRNAs significantly differentially regulated by spaceflight, of which many genes were found to belong to pathways involved in muscle growth and adaptation. Spaceflight significantly altered the levels of mRNAs involved with the PI3kinase/Akt/mTOR pathway: the PI3-kinase regulatory subunit polypeptide 1 , pi $3 \mathrm{kr} 1 / \mathrm{p} 85 \alpha$, the forkhead box O1 (FoxO1), transcription factor, the muscle-specific ubiquitin ligase F-box only protein 32 (MAFbx/atrogin1), and the ubiquitin-conjugating enzyme E2 variant 2 mRNAs were increased; Insulin receptor substrate-1 (IRS-1) mRNA levels were decreased in space flown mouse gastrocnemius muscles. Genes in the TNF- $\alpha / N F-\kappa B$ signaling pathway and the calcineurin/nuclear factor of activated T cells (NFAT) pathway were also affected: the TNF- $\alpha$ downstream target TNF- $\alpha$-induced protein 2 mRNA and the NF-kB inhibitor nuclear factor B light chain gene enhancer in B cells inhibitor $\alpha(\mathrm{Nfkbia} / \mathrm{I \kappa B} \alpha) \mathrm{mRNA}$ were significantly increased, whereas mRNA levels of the NFAT cytoplasmic, calcineurindependent 3 (Nfatc3) transcription factor were significantly decreased in SF gastrocnemius. In addition, mRNAs for three members of the CAAT/enhancer binding protein (C/EBP) family of transcription factors, C/EBP- $\alpha, C / E B P-\beta$, and C/EBP- $\delta$ were also increased in SF gastrocnemius. They found that space flight increased myostatin (which limits muscle growth) mRNA and decrease the mRNA levels of myostatin inhibitor FSTL3. They also found that mRNA levels of the slow oxidative fiber-associated transcriptional coactivators, peroxisome proliferator activated receptor alpha (PPAR- $\alpha$ ) and the PPAR- $\gamma$ coactivator $1 \alpha$ (PGC1- $\alpha$ ) decreased in space-flight. They concluded that spaceflight induced significant changes in mRNA expression of genes associated with muscle growth and fiber type toward a less oxidative phenotype (Allen et al 2009).

Chopard et al (2009) performed a genome-wide gene expression analysis of female skeletal muscles during 60 days of bed rest with and without exercise or dietary protein supplementation as countermeasures. They investigated the effects of long-term bed rest on the gene expression of soleus (SOL) and vastus lateralis (VL) muscles in healthy women using a customized microarray containing 6,681 muscles-relevant genes. They found clusters of genes involved in nucleic acid and protein metabolism were upregulated and that encoding components involved in energy metabolism were downregulated. Counter measures (exercise and nutrition) had some compensatory effects on gene expression profiles.

Reich et al (2010) examined the global gene expression patterns of the left vastus lateralis muscle in seven sedentary men following $48 \mathrm{~h}$ unloading via unilateral lower limb suspension and $24 \mathrm{~h}$ reloading. Microarray analysis of gene expression changes were used 
for the identification of enriched functions and canonical pathways. They found that the highest ranked canonical pathways were related to protein ubiquitination and oxidative stress response pathways. Gene functions related to mitochondrial metabolism were the most significantly downregulated. The increases in mRNA for ubiquitin proteasome pathway-related E3 ligase and stress response gene heme oxygenase-1 as well as extracellular matrix (ECM) component COL4A3 were confirmed by qRT-PCR. The unloading associated gene expression patterns were not reversed on reloading.

The ten studies discussed above made good use of microarray biotechnology in their respective studies. Out of the ten studies, we found seven that had gene lists of some form that could be further analyzed. Among the seven gene lists, a few genes were reported in more than one study. Fibronectin (FN1) was identified by several microarray studies in muscle. In space-flown rat muscles, FN1 was down-regulated (Nikawa et al, 2004) and it was down-regulated in HLS rats as well (Dapp et al, 2004). Interestingly, FN1 was upregulated in the recovery time points in Dapp et al. FN1 was also up-regulated in women exposed to bed rest (Chopard et al, 2009). ACADVL was found to be down-regulated both in rat (Stein et al, 2002) and human muscles (Chopard et al, 2009). Another four genes were identified in the same directions between a study in mouse and a study in rat: MT1, MT2, and PIM3 were upregulated, whereas MARCKS was down regulated in both studies (Nikawa et al, 2004; Allen et al, 2009). In addition, CYR61 gene was identified to be upregulated by a study in mouse (Allen et al, 2009) and a study in rat muscles (Nikawa et al, 2004). I also did DAVID analysis for all the genes pooled from the ten studies and found that 32 pathways were involved (data not shown). This large variation could at least in part be due to the heterogeneity of the study conditions. The factors discussed in the immune and bone sections also apply.

\section{Microarray analysis of microgravity exposed other cells}

Exposure of rat bone marrow mesenchymal stems cells (rBMSC) to HMGE simulated microgravity study found that BMSC proliferation and osteogenesis decreased and the cells were growth arrested in the G0/G1 phase of cell cycle (Dai et al 2007). Data from their microarray (CapitalBio Corporation) analysis confirmed that rBMSC proliferation and osteogenesis gene activities decreased under simulated microgravity. Insulin-like growth factor-I, epidermal growth factor, and basic fibroblastic growth factor that normally stimulated rBMSC proliferation had only a marginal effect in the simulated microgravity..

Sheyn et al (2010) using Affymetrix microarrays examined simulated microgravity (RWV) effect on human mesenchymal stem cells. The cells were seeded on microcarrier beads and placed in a RWV bioreactor, which was rotated at $16 \mathrm{rpm}$ to simulate a microgravity environment. They identified 882 genes that were down regulated and 505 genes were upregulated by 2 fold or above and with a P value of 0.05 or less. They identified a large number of gene clusters responded to microgravity. In agreement with previous studies, their microarray data showed a general trend of less osteogenesis and more adipogenesis when hMSCs cells were cultured in simulated microgravity. Most of the extracellular matrix related genes were downregulated. They identified many genes that were involved in the actin cytoskeleton such as COL1A1, COL1A2, FN1, SPARC, CTGF, and IGFBP3, were downregulated. The mRNA of several growth and differention factors such as fibroblast growth factor, vascular endothelial growth factor, insulin-like growth factor-related proteins, and 
bone morphogenetic protein (BMP)6 were downregulated. Most osteogenic genes (such as BMP6, osteonectin, and collagen type I) were downregulated, whereas most adipogenic genes were upregulated.

A recent study using hematopoietic stem cells by Fridley et al (2010) was not a microgravity study per se. Instead it was a comparative study of stirred tank bioreactors and RWV bioreactors. They studied how these devices would work in the formation of embryoid bodies and the generation of hematopoietic progenitor cells. For the RWV study they ran the bioreactor samples at speeds ranging from $10 \mathrm{rpm}$ to $40 \mathrm{rpm}$. They used Roche Nimblegene 4 plex microarrays (72k) for the study. They did discuss some of the genes that were differentially regulated, but they did not publish a full gene list. One gene that was significantly down-regulated was E-Cadherin (Fridley et al, 2010).

Clement et al, using Agilent 22K Human 1A microarrays, examined skin cells (HEK001) for their response to simulated microgravity over the course of 3,4,9, and 10 days followed by recovery from SMG in normal cell culture conditions for 15, 50, and 60 days. A total of 162 genes $(\mathrm{P}<0.05)$ were differentially regulated by at least 2 fold at some point during the time course. They also used Northern blotting to both qualitatively and quantitatively verify their data. The genes that were analyzed showed a statistical correlation with the microarray data ranging from 0.69 to 0.97 . Interestingly, $80 \%$ of the differentially expressed genes recovered from 4 days SMG exposure after 15 days in normal cell culture conditions. Genes that were exposed to 9 days SMG required more than 50 days to recover to pre-exposure levels. Also of interest, HLA-G, a key gene in cellular immune response suppression, was found to be significantly up-regulated during the recovery phase (Clement et al 2008). This study indicates that longer term exposure to microgravity may have long term affects on the body even after returning to normal gravity. Further studies on microgravity exposure and subsequent recovery should be carried out.

The effect of microgravity on the nervous system and brain at the molecular level is still not well understood. Frigeri et al examined gene expression in mouse brain after 2 weeks hindlimb supesension (Frigeri et al 2008). Using 27K cDNA microarrays, they found 592 statistically significant genes with 1.5 fold or higher differential regulation. Hind-limb suspension also seems to affect the pathways involved in learning and memory as well as blood coagulation. They found that hind-limb suspension causes a more hyper-coagulative state and an increased risk of venous thrombosis (Frigeri et al 2008). In a recent study PC12 cells were exposed to 4 days SMG to analyze oxidation sensitive genes in microgravity (Kwon et al 2006). They found that 65 genes were up-regulated and 39 were down-regulated as a result of exposure to SMG. They found that genes involved in DNA repair and replication, cell proliferation, apoptosis, molecular transport, and oxidative phosphorylation were affected by exposure to SMG.

A 2002 study of human fibroblast grown onboard the space shuttle (STS-93) in 1999 identified changes in expression of 10 genes in the TNF or IL gene families. For this study, they chose 202 genes which were then spotted on to a nylon membrane. They did verify their results on some genes with semi-quantitative PCR with a correlation of 0.89 . The genes identified are involved in the regulation of bone density or proinflammatory status (Semova et al 2002).

Some of the first microarray studies of space flown cells was done using renal cortical cells flown on STS-90 (Hammond et al, 1999). They applied a high throughput microarray system 
to study gravity-induced gene-expression changes in human renal cells and found 1632 out of 10,000 genes changed as a result of exposure to microgravity (Hammond et al, 2000).

Kitamoto et al studied Xenopus A6 cells grown in RPM simulated microgravity environment and examined gene expression using customized Agilent 8K Xenopus laevis DNA microarrays (Kitamoto et al, 2004, Kitamoto et al, 2005). They found that 52 out of 8091 genes examined showed differential regulation. Their time course data showed interesting gene expression patterns of microgravity effect and cellular adaptation. They also found that SPARC was down-regulated Xenopus A8 cell lines (Ikuzawa and Asashima 2008). Their data combined with previous observations (Kitamoto et al, 2005) lead them to conclude that SPARC might play a key role in response to microgravity (Ikuzawa and Asashima 2008). Down-regulation of SPARC and SPARC related genes has also been observed in human mesenchymel stem cells grown in SMG (Sheyn et al, 2010).

Liver cells have also been studied in SMG. Both of the SMG studies on liver cells were carried out using HepG2 cells (Clement et al, 2007; Khaoustov 2001). Both studies showed that liver cells grown in a RWV caused altered gene expression patterns. The Clement study used Agilent 22K human 1A microarrays to study HepG2 cells. They identified 139 genes which were differentially regulated with a fold change of $>1.5$ and $P<0.01$. Khaoustov et al used 6K Human Array containing 6144 genes showed that 95 genes were differentially regulated. More systematic studies would be needed in further studying microgravity effects on liver cells.

\section{Towards the identification of major space genes}

A main focus of this chapter was to try to identify potential major space genes by reviewing gene expression profiles, compare and contrast the expression profiles of cells from different lineages of different organisms exposed to various microgravity conditions. My original hypothesis was that it could be possible that a common set of key microgravity sensitive genes in different cells would be preferentially altered in microgravity conditions. The identification of this common set of genes might lead to the identification of "major space genes" that together play a major check-and-balance role ultimately determining the outcome of a cell, or an organism such as an individual person, in the response to microgravity conditions. This is analogous to areas of cancer research resulting in the identification of growing numbers of major cancer genes (oncogenes and tumor suppressor genes) that are directly involved in the determination the fate of a cell---whether a cell becomes cancerous or not. I therefore believed that a systematic examination of molecular alterations of cells under microgravity conditions would enhance our knowledge of cellular responses to microgravity and the underlying mechanisms. Since cells of different organ or tissue systems may be affected by this environmental factor differently, studying and comparing the cellular response to such gravity changes using various cell lines of different lineage or tissue origin would generate a comprehensive database of cellular activity alteration associated with microgravity, and the identification of major space genes. This would provide scientific basis for therapeutic intervention aimed to prevent and correct abnormalities resulting from space flight.

Examining high throughput microarray data as well as other gene expression data from cells and organisms exposed to microgravity, there were a great many differentially 
regulated genes that showed little or no commonality across closely related studies. In most study areas such as immune, bone, and muscle response to microgravity, there was overall very little commonality or overlap among the reports at the individual gene expression level. However, when looked at gene pathways through DAVID analysis, relatively focused and very insightful pathways were identified for the microarray based analysis of microgravity effects on the immune and bone cells. Would it be that major space pathways rather than major space genes are playing key roles in microgravity response? Typically, there are many gene components in a pathway. It is possible that genes in a pathway can have various levels of activity in response to an environmental challenge and the level of activity of the pathway is optimized to be able to best adapt to environmental change by adjusting component genes activities. Whatever the case, it is too early to conclude from such an initial attempt of cross platform and cross species examinations.

Nonetheless, as part of the identification of space genes, I decided to make a further attempt to compare the gene lists from the microarray studies in mammals that were discussed in this chapter. I compared gene lists from these studies to determine what genes might be common among these studies. There were a large number of differences between the gene lists. This has been shown to be the case in other studies examining microarray experiments between labs and across platforms. These variations are not surprising considering the significant variations between experiments. First, the type of cells used for the studies were very different. These cells included rat muscle, mouse muscle, Xenopus renal, and human liver, renal, keratinocyte, fibroblasts, etc. The methods for studying microgravity were different. These included Random Positioning Machine (RPM), Rotating Wall Vessel (RWV) bioreactors, bed rest, hind limb suspension, as well as space flown. Finally, and perhaps more importantly, the microarray platforms had major variations. All of these variables make it particularly difficult to compare data. For the purpose of this discussion, we decided to include any gene on our final list of potential "space genes" if it appeared on two or more gene lists of the studies we examined. Using this loosely defined criterion, the initial potential candidates for "space genes" were subjected to bioinformatics analysis.

Using the DAVID Bioinformatics Resources, I processed these genes together to identify relevant KEGG pathways (Table 4). The KEGG Pathways and Gene Ontologies were included in the tables if they were considered to be statistically significant $(\mathrm{P} \leq 0.05)$.

The pathway table shows that Extracellular Matrix-Receptor Interaction and Focal Adhesion Pathways are two important pathways. Both have been identified as pathways that may be affected by Microgravity (Ingber 1998).

As part of the attempt to identify and create a list of potential space genes from the microarray based microgravity studies, I decided to analyze a variety of gene lists from these studies. First, I limited the scope of the bioinformatics analysis to mammalian cells. I then examined all of these studies to identify the ones that had useable gene lists. Out of a total of 36 mammalian studies, I identified 26 studies that could be used for this purpose. If a gene appeared as differentially regulated in at least four of these studies, it would be included in the candidate gene list. This yielded a list of 8 potential space genes, name Putative Space Genes (Table 5).

The initial candidate major space genes thus identified in Table 5 (for which I briefly discussed while reviewing each of the involved studies) will provide a clue for further 
scrutiny in future more systematic studies. I believe that systematic examination of molecular alterations of cells under microgravity conditions will enhance our knowledge of cellular responses to gravity changes and the underlying mechanisms.

\begin{tabular}{|ll|}
\multicolumn{2}{c}{ KEGG Pathways } \\
\hline ECIM-receptor Interaction & CD44, COL3A1, COL1A2, ITGB5, COL1A1, THES1, \\
& THBS2, COL11A1, FN1 \\
Focal adhesion & ACTB, COL3A1, COL1A2, ITGB5, COL1A1, THBS1, \\
& THBS2, COL11A1, FN1 \\
Hypertrophic cardiomyopathy (HCM) & ACTB, ACTC1, IL6, TGFB3, ITGB5, TPM1 \\
TGF-beta signalling pathway & BMP4, INHBA, TGFB3, DCN, THBS1, THBS2 \\
Dilated cardiomyopathy & ACTB, ACTC1, TGFB3, ITGB5, TPM1 \\
Prion diseases & IL6, HSPA1A, IL1A \\
Pathways in cancer & WNT5A, BMP4, IL6, TGFB3, COH1, MMP1, FN1 \\
Glycolysis / Gluconeogenesis & HK2, PCK2, ENO1 \\
Bladder cancer & CDH1, THBS1, MMP1 \\
Pathogenic Escherichia coli infection & ACTB, COH1, TUBB3 \\
\hline
\end{tabular}

Table 4. KEGG Pathways identified using the DAVID Bioinformatics Resources.

\section{Putative Space Genes}

\begin{tabular}{|c|c|c|}
\hline Gene Symbol & Gene Description & Species* \\
\hline \multicolumn{3}{|l|}{4 studies } \\
\hline CD44 & antigen (homing funciton snd Indian blood group system) & $H, M$ \\
\hline MARCKS & Myristoylated alanine-rich protein kinase C substrate & $R, M, X$ \\
\hline \multicolumn{3}{|l|}{5 Studies } \\
\hline FN1 & Fibronectin & $H, R, M$ \\
\hline TUBA1 & Tubulin, Alpha 1 & $H, M, X$ \\
\hline \multicolumn{3}{|l|}{6 Studies } \\
\hline CTGF & Connective tissue growth factor & $H, M, X$ \\
\hline CYR61 & Cysteine-rich, angionic inducer, 61 & $H_{1}, \mathrm{R}, \mathrm{M}, \mathrm{X}$ \\
\hline MT2 & Metallothionein 2 & $H, R, M$ \\
\hline \multicolumn{3}{|l|}{7 Studies } \\
\hline MT1 & Metallothionein 1 & $H, R, M, X$ \\
\hline
\end{tabular}

Table 5. List of putative space genes.

\section{References}

Atkov, O. (1992). Some medical aspects of an 8 month's space flight. Advances in Space Research. Vol.12, No.1, pp. 343-345.

Aponte, V.M., Finch, D.S. \& Klaus, D.M. (2006). Considerations for non-invasive in-flight monitoring of astronaut immune status with potential use of MEMS and NEMS devices. Life Sciences. Vol.79, pp. 1317-1333.

Amin, S. (2010) Mechanical factors and bone health: effects of weighlessness and neurological injury. Current Rheumatology Reports. Vol.12, No.3, pp. 170-176

Allen, D.L., Bandstra, E.R., Harrison, B.C., Thorng, S., Stodieck, L.S., Kostenuik, P.J., Morony, S., Lacey, D.L., Hammond, T.G., Leinwand, L.L., Argraves, W.S., Bateman, T.A. \& Barth, J.L. (2009). Effects of spaceflight on murine skeletal muscle gene expression. Journal of Applied Physiology. Vol.106, pp. 582-595 
Aubert, A.E., Beckers, F. \& Verheyden, B. (2005). Cardiovascular function and basics of physiology in microgravity. Acta Cardiologica. Vol.60, No.2, pp. 129-151.

Aviles, H., Belay, T., Vance, M., Sun, B. \& Sonnenfeld, G. (2004). Active hexose correlated compound enhances the immune function of mice in the hindlimb-unloading model of spaceflight conditions. Journal of Applied Physiology. Vol.97, pp. 1437-1444

Beller, G., Belavy, D.L., Sun, L. \& Armbrecht, G. (2011). WISE-2005: Bed-rest induces changes in bone mineral density in women during 60 days simulated microgravity. Bone. doi:10.1016/j.bone.2011.06.021

Boonyaratanakornkit, J.B., Cogoli, A., Li, C.F., Schopper, T., Pippia, P., Galleri, G., Meloni, M.A. \& Hughes-Fulford, M. (2005). Key gravity-sensitive signaling pathways drive T cell activation. FASEB Journal. Vol.19, pp. 2020-2022

Borchers, A.T., Keen, C.L. \& Gershwin, M.E. (2002) Microgravity and immuneresponsiveness: implications for space travel. Nutrition. Vol.18, pp. 889-898.

Capulli, M., Rufo, A., Teti, A. \& Rucci, N. (2009) Global transcriptome analysis in mouse calvarial osteoblasts sets of genes regulated by modeled microgravity and identifies a "mechanoresponsive osteoblast gene signature". Journal of Cellular Biochemistry. Vol.107, No.2, pp. 240-252

Carmeliet, G., Nys, G., Stockmans, I. \& Bouillon, R. (1998). Gene expression related to the differentiation of osteoblastic cells is altered by microgravity. Bone. Vol.22, No. 5 Suppl., pp. 139S-143S

Clement, J.Q. (2010). Microarray profiling of genome-wide expression regulation in response to environmental exposures, In: A Practical Guide to Bioinformatics Analysis, G.P.C. Fung, pp. 22-40, Iconcept Press, ISBN 978-0-9807330-2-0, Brisbane

Clement, J.Q., Lacy, S.M. \& Wilson, B.L. (2007). Genome-wide gene expression profiling of microgravity effect on human liver cells, Journal of Gravitational Physiology. Vol.14, pp.P121-122

Clement, J.Q., Lacy, S.M. \& Wilson, B.L. (2008). Gene expression profiling of human epidermal keratinocytes in simulated microgravity and recovery cultures. Genomics, Proteomics, and Bioinformatics. Vol.6, No.1:8-28.

Coleman, C.G., Gonzalez-Villalobos, R.A., Allen, P.A., Johanson, K., Guevorkian, K., Valles, J.M. \& Hammond, T.G. (2007). Diamagnetic levitation changes, growth, cell cycle, and gene expression of saccharomyces cerevisiae. Biotechnology and Bioengineering. Vol.98, No.4, pp. 854-863 Caillit-Augusseau, A., Vico, L., Heer, M., Voroviev, D., Sourberbielle, J., Zitterman, A., Alexandre, C. \& Lafage-Proust, M. (2000). Space flight is associated with rapid decreases of undercarboxylated Osteocalcin and increases of markers of bone resorption without changes in their circadian variation: observations in two Cosmonauts. Clinical Chemistry. Vol.46, pp. 1136-1143

Collet, P., Uebelhart, D., Vico, L., Moro, L., Hartmann, D., Roth, M. \& Alexandre, C. (1997). Effects of 1- and 6- month spaceflight on bone mass and biochemistry in two humans. Bone. Vol.20, No.6, pp. 547-551

Cogoli, A. (1993). Space flight and the immune system. Vaccine. Vol.11, No.5, pp. 496-503.

Collet, P. et al (1997). Effects of 1- and 6-month spaceflight on bone mass and biochemistry in two humans. Bone. Vol.20, pp. 547-551.

Congdon, C.C., Allebban, Z., Gibson, L.A., Kaplansky, A., Strickland, K.M., Jago, T.L., Johnson, D.L., Lange, R.D. \& Ichiki, A.T. (1996). Lymphatic tissue changes in rats 
flown on Spacelab Life Sciences-2. Journal of Applied Physiology. Vol.81, No.1, pp. 172-177.

Crabbe, A., Pycke, B., Van Houdt, R., Monsieurs, P., Nickerson, C., Leys, N \& Cornelis, P. (2010). Reponse of Pseudomonas aeruginosa PAO1 to low shear modeled microgravity involves AlgU regulation. Environmental Microbiology. Vol.12, No.6, pp. 1545-1564

Crucian, B.E., Cubbage, M.L. \& Sams, C.F. (2000) Journal of Interferon Cytokine Research. Vol.20, No.6, pp. 547-556

Dai, Z.Q., Wang, R., Ling, S.K., Wan, Y.M. \& Li, Y.H. (2007). Simulated microgravity inhibits the proliferation and osteogenesis of rat bone marrow mesenchymal stems cells. Cell Proliferation. Vol.40, pp. 671-684

Dalma-Weiszhausz, D.D., Warrington, J., Tanimoto, E.Y. \& Miyada, C.G. (2006). The Affymetrix GeneChip ${ }^{\circledR}$ platform: an overview. Methods in Enzymology. Vol.410, pp. 3-28

Dapp, C., Schmutz, S., Hoppeler, H. \& Fluck, M. (2004). Transcriptional reprogramming and ultrastructure during atrophy and recovery of mouse soleus muscle. Physiologic Genomics. Vol.20, pp. 97-107

Davidson, J.M., Aquino, A.M., Woodward, S.C. \& Wilfinger, W.W. (1999). Sustained microgravity reduces wound healing and growth factor responses in the rat. FASEB Journal. Vol.13, No.2, pp. 325-329

Fan, J.B., Gunderson, K.L., Bibikova, M., Yeakley, J.M., Chen, J., Garcia, E.W., Lebruska, L.L., Laurent, M., Shen, R. \& Barker, D. (2006) Illumina universal bead arrays. Methods in Enzymology. Vol.410, pp. 57-73

Fan, X., Lobenhofer, E.K., Chen, M., Shi, W., Huang, J., Luo, J., Zhang, J., Walker, S.J., Chu, T.M., Li, L., Wolfinger, R., Bao, W., Paules, R.S., Bushel, P.R., Li, J., Shi, T., Nikolskaya, T., Nikolsky, Y., Hong, H., Deng, Y., Cheng, Y., Fang, H., Shi, L. \& Tong, W. (2010) Consistency of predictive signature genes and classifiers generated using different microarray platforms. The Pharmacogenomics Journal. Vol.10, pp. 247-257

Fitts, R.H., Desplanches, D., Romatowski, J.G. \& Widrick, J.J. (2000). Physiology of a microgravity environment. Invited review: microgravity and skeletal muscle. . Journal of Applied Physiology. Vol.89, pp. 823-839

Fridley, K.M., Fernandez, I., Li, M.A., Kettlewell, R.B. \& Roy, K. (2010). Unique differentiation profile of mouse embryonic stem cells in rotary and stirred tank bioreactors. Tissue Engineering: Part A. Vol.16, No.11, pp. 3285-3298

Frigeri, A., Iacobas, D.A., Iacobas, S., Nicchia, G.P., Desaphy, J.F., Camerino, D.C., Svelto, M. \& Spray, D.C. (2008). Effect of microgravity on gene expression in mouse brain. Experimental Brain Research. Vol.191, pp. 259-300

Fritsch-Yelle, J.M., Charles, J.B., Jones, M.M. \& Wood, M.L. (1996). Microgravity decreases heart rate and arterial pressure in humans. Journal of Applied Physiology. Vol. 80, No.3, pp. 910-914.

Gould, C.L., Lyte, M., Williams, J., Mandel, A.D. \& Sonnenfeld, G. (1987) Inhibited interferon-gamma but normal interleukin-3 production from rats flown on the space shuttle. Aviation, Space and Environmental Medicine. Vol.58, No.10, pp. 983-986

Gridley, D.S., Nelson, G.A., Peters, L.L., Kostenuik, P.J., Bateman, T.A., Morony, S., Stodieck, L.S., Lacey, D.L., Simske, S.J. \& Pecaut, M.J. (2003). Selected contribution: effects of 
spaceflight on immunity in the C57BL/6 mouse. II. Activation, cytokines, erythrocytes, and platelets. Journal of Applied Physiology. Vol.94, pp. 2095-2103.

Gridley, D.S., Slater, J.M., Luo-Owne, X., Rizvi, A., Chapes, S.K., Stodieck, L.S., Ferguson, V.L. \& Pecaut, M.J. (2009). Spacefilght effects on T lymphocyte distribution, function and gene expression. Journal of Applied Physiology. Vol.106, pp. 194-202

Hammond, T.G. \& Hammond, J.M. (2001). Optimized suspension culture: the rotating-wall vessel. American Journal of Physiology-Renal Physiology . Vol.281, pp. F12-F25

Hammond, T. G., Lewis, F.C., Goodwin, T.J., Linnehan, R.M., Wolf, D.A., Hire, K.P., Campbell, W.C., Benes, E., O’Reilly, K.C., Globus, R.K. \& Kaysen, J.H. (1999). Gene expression in space. Nature Medicine Vol.5, No.4, pp. 359-359

Hammond, T.G., Benes, E., O'Reilly, K.C., Wolf, D.A., Linnehan, R.M., Taher, A., Kaysen, J.H., Allen, P.L. \& Goodwin, T.J. 2000. Mechanical culture conditions effect gene expression: gravity-induced changes on the space shuttle. Physiological Genomics Vol.3, pp. 163-173

Handley, D., Serban, N., Peters, D., O'Doherty, R., Field, M., Wasserman, L., Spirtes, P., Scheines, R. \& Glymour, C. (2004). Evidence of systematic expressed sequence tag IMAGE clone cross-hybridization on cDNA microarrays. Genomics. Vol.83, pp. 1169-1175

Henriksen, E.J. \& Tishler, M.E. (1988) Glucose uptake in rat soleus: effect of acute unloading and subsequent reloading. Journal of Applied Physiology. Vol.64, pp. 1428-1432

Hoson, T., Kamisaka, S., Masuda, Y., Yamashita, M. \& Buchen, B. (1997). Evaluation of the three-dimensional clinostat as a simulator of weightlessness. Planta. Vol.203, pp. S187-S197

Hoson, T., Kamisaka, S., Miyamoto, K., Ueda, J., Yamashita, M. \& Masuda, Y. (1993). Microgravity Science and Technology. Vol.6., No.4, pp. 278-281

Huang, D.W., Sherman, B.T. \& Lempicki, R.A. (2009a). Systematic and integrative analysis of large gene lists using DAVID Bioinformatics Resources. Nature Protocols. Vol.4, No.1, pp. 44-57.

Huang, D.W., Sherman, B.T. \& Lempicki, R.A. (2009b). Bioinformatics enrichment tools: paths toward the comprehensive functional analysis of gene lists. Nucleic Acids Research. Vol.37, No.1, pp. 1-13

Hurley, M.M. \& Lorenzo, J.A. (2004). Systemic and Local Regulators of Bone Remodeling, In: Bone Formation, Bonner, F. \& Farach-Carson, M.C., pp. 44-70, Springer-Verlag, ISBN 1-85233-717-6, London

Hughes-Fulford, M. (2003). Function of the cytoskeleton in gravisensing during spaceflight. Advances in Space Research. Vol.32, No.8, pp. 1585-1593

Hughes-Fulford, M. (2002). Physiological effects of microgravity on osteoblast morphology and cell biology. Advances in Space Biology and Medicine. Vol.8, pp. 129-157

Ikuzawa, M. \& Asashima, M. (2008). Global expression of simulated microgravityresponsive genes in Xenopus liver cells. Zoological Science. Vol.25, No. 8, pp. 828-837

Jagoe, R.T., Lecker, S.H., Gomes, M. \& Goldberg, A.L. (2002). Patterns of gene expression in atrophying skeletal muscles: response to food deprivation. FASEB. Vol.16, pp. 16971712

Keyak, J.H., Koyama, A.K., LeBlanc, A. \& Lang, T.F. (2009). Reduction in proximal femoral strength due to long-duration spaceflight. Bone. Vol.44, pp. 449-453 
Khaoustov, V.I., Risin, D., Pellis, N.R. \& Yoffe, B. (2001). Microarray analysis of genes differentially expressed in HepG2 cells cultured in simulated microgravity. In Vitro Cellular \& Developmental Biology - Animal. Vol.37, No.2, pp. 84-88Hammer, B.E., Kidder, L.S., Williams, P.C. \& Xu. W.W. (2009). Microgravity Science and Technology. Vol.21, No.4, pp. 311-318.

Kitamoto, J., Fukui, A. \& Asashima, M. (2004). Global and temporal regulation of gene expression in Xenopus kidney cells in response to presumed microgravity generated by 3D clinostats. Biological Sciences in Space. Vol.18, pp. 152-153

Kitamoto, J., Fukui, A. \& Asashima, M. (2005). Temporal regulation of global gene expression and cellular morphology in Xenopus kidney cells in response to clinorotation. Advances in Space Research. Vol.35, pp. 1654-1661.

Klaus D.M. (2001). Clinstats and bioreactors. Gravitational Space Biology Bulletin. Vol.14, No2., pp. 55-64

Klaus, D.M. \& Howard, H.N. (2006). Antibiotic efficacy and microbial virulence during space flight. Trends in Biotechnology. Vol.24, pp. 131-136

Kwon, O., Sartor, M., Tomlinson, C.R., Millard, R.W., Olah, M.E., Sankovic, J.M. \& Banerjee, R.K. (2006). Effect of simulated microgravity on oxidation-sensitive gene expression in PC12 cells. Advances in Space Research. Vol.36, No.6, pp. 1168-1176

Lang, T.F., LeBlanc, A.D., Evans, H.J. \& Lu, Y. (2006). Adaptation of the proximal femur to skeletal reloading long-duration spaceflight. Journal of Bone and Mineral Research. Vol.21, No.8, pp. 1224-1230.

Leach, C.S. (1990). Medical considerations for extending human presence in space. Acta Astronautica. Vol.21, pp. 659-666.

LeBlanc, A.D., Spector, E.R., Evans, H.J. \& Sibonga, J.D. (2007). Skeletal responses to space flight and the bed rest analog: a review. Journal of Musculoskeletal and Neuronal Interactions. Vol.7, No.1, pp. 33-47

Lebsack, T.W., Fa, V., Woods, C.C., Gruener, R.. Manziello, A.M., Pecaut, M.J., Gridley, D.S., Stodieck, L.S., Ferguson, V.L. \& DeLuca, D. (2010). Microarray analysis of spaceflown murine thymus tissue reveals changes in gene expression regulating stress glucocorticoid receptors. Journal of Cellular Biochemistry. Vol.110, pp. 372-381

Lewis, M.L., Cubano, L.A., Zhao, B., Dinh, H.K., Pabalan, J.G., Piepmeier, E.H. \& Bowman, P.D. (2001). cDNA microarray reveals altered cytoskeletal gene expression in spaceflown leukemic T lymphocytes (Jurkat). FASEB Journal. Vol.15, No.10, pp. 17831785

Mack, P.B., LeChange, P.A., Vose, G.P. \& Vogt, F.B. (1967). Bone demineralization of foot and hand of gemini-titan IV, V and VII astronauts during orbital flight. American Journal of Roentgenology, Radium Therapy and Nuclear Medicine. Vol.100, No.3, pp. 503-11

MAQC Consortium (2006). The MicroArray quality control (MAQC) project shows interand intraplatform reproducibility of gene expression measurements. Nature Biotechnology. Vol.24, No.9, pp. 1151-1161

Marcu, O., Lera, M.P., Sanchez, M.E., Levic, E., Higgins, L.A., Shmygelska, A., Fahlen, T.F., Nichol, H. \& Bhattacharya, S. (2011). Innate immune responses of Drosophila Melanogaster are altered by Spaceflight. PLoS One, Vol.6, No.1, e15316

Martin, I.P., et al 1988. Influences of spaceflight on rat skeletal muscle. . Journal of Applied Physiology. Vol.65, pp. 2318-2325 
Mazzatti, D.J., Smith, M.A., Oita, R.C., Lim, F.L., White, A.J. \& Reid, M.B. (2008). Muscle unloading-induced metabolic remodeling is associated with acute alterations in PPAR $\delta$ and UCP-3 expression. Physiological Genomics. Vol.34, pp. 149-161

Meloni, M.A., Galleri, G., Carta, S., Negri, R., Costanzo, G., de Sanctis, V. Cogoli, A. \& Pippia, P. (2002). Preliminary study of gene expression levels in human T-cells exposed to cosmic radiations. Journal of Gravitational Physiology. Vol.9, No.1, pp. P291-292.

Nakamura, H., Kumei, Y., Morita, S. Shimokawa, H., Ohya, K. \& Shinomiya, K. (2003) Suppression of osteoblastic phenotypes and modulation of pro- and anti-apoptotic features in normal human osteoblastic cells under a vector-averaged gravity condition. Journal of Medical and Dental Sciences. Vol.50, No.2, pp. 167-176

Narici, M.V. \& de Boer, M.D. (2011). Disuse of the musculo-skeletal system in space and on earth. European Journal of Applied Physiology. DOI 10.1007/s00421-010-1556-x McPhee, J (2006). Life sciences research standardization. Journal of Gravitational Physiology. Vol.13, pp. 59-72.

Nath, R., Kuman, D., Li, T. \& Singal, P.K. (2000). Metallothioneins, oxidative stress and the cardiovascular sytem. Toxicology. Vol.155, pp. 17-26

Nickerson, C.A., Ott, C.M., Wilson, J.W., Ramamurthy, R., LeBlanc, C.L., Honer zu Bentrup, K., Hammond, T. \& Pierson, D.L. (2003). Low-shear modeled microgravity: a global environmental regulatory signal affecting bacterial gene expression, physiology, and pathogenesis. Journal of Microbiological Methods. Vol.54, No.1, pp. 1-11.

Nikawa, T., Ishidoh, K., Hirasaka, K., Ishihara, I., Ikemoto, M., Kano, M., Kominami, E., Nonaka, I., Ogawa, T., Adams, G.R., Baldwin, K.M., Yasui, N., Kishi, K. \& Takeda, S. (2004). Skeletal muscle gene expression in space-flown rats. FASEB Journal. Vol.18, pp. 522-524

Pardo, S.J., Patel, M.J., Skyes, M.C., Platt, M.O., Boyd, N.L., Sorescu, G.P., Xu, M., van Loon, J.J.W.A., Wang, M.D. \& Jo, H. (2005). Simulated microgravity using the random positioning machine inhibits differentiation and alters gene expression profiles of 2T3 preosteoblasts. American Journal of Cell Physiology. Vol.288, pp. C1211-C1221

Patel, M.J., Liu, W., Sykes, M.C., Ward, N.E., Risin, S.A., Risin, D. \& Jo, H. (2007). Identification of mechanosensitive genes in osteoblasts by comparative microarray studies using the rotating wall vessel and the random positioning machine. Journal of Cellular Biochemistry. Vol.101, pp. 587-599

Patel, M.J., Chang, K.H., Skyes, M.C., Talish, R., Rubin, C. \& Jo, H. (2009). Low magnitude and high frequency mechanical loading prevents decreased bone formation responses of 2T3 preosteoblast. Journal of Cellular Biochemistry. Vol.106, pp. 306-316

Pippia, P., Sciola, L., Cogoli-Greuter, M., Meloni, M.A., Spano, A. \& Cogoli, A. (1996) Activation signals of T lymphocytes in microgravity. Journal of Biotechnology. Vol.47, pp. 215-222

Qian, A., Di, S., Gao, X., Zhang, W., Tian, Z., Li, J., Hu, L., Yang, P., Yin, D. \& Shang, P. (2009). cDNA microarray reveals the alterations of cytoskeleton-related genes in osteoblasts under high mangneto-gravitational environment. Acta Biochimica et Biophysica Sinica. Vol.41, No.7, pp. 561-577

Qiao, M., Shapiro, P., Kumar, R. \& Passaniti, A. (2004). Insulin-like growth factor-1 regulates endogenous RUNX2 activity in endothelial cells through phosphatidylinositol 3- 
kinase/ERK-dependent and Akt-independent signaling pathway. Journal of Biological Chemistry. Vol.279., No. 41, pp. 42708-42718

Reich, K.A., Chen, Y.W., Thompson, P.D., Hoffman, E.P. \& Clarkson, P.M. (2010). Fortyeight hours of unloading and $24 \mathrm{~h}$ of reloading lead to changes in global gene expression patterns related to ubiquitination and oxidative stress in humans. Journal of Applied Physiology. Vol.109, No.5, pp. 1404-1415

Rennie, M.J., Selby, A., Atherton, P., Smith, K., Kumar, V., Glover, E.L. \& Philips, S.M. (2010). Facts, noise and wishful thinking: muscle protein turnover in aging and human disuse atrophy. Scandinavian Journal of Medicine and Science in Sports. Vol.20, pp. 5-9

Rykova, M.P., Sonnenfeld, G., Lesnyak, A.T., Taylor, G.R., Meshkov, D.C., Mandel, A.D., Medvedev, A.E., Berry, W.D., Fuchs, B.B. \& Konstantinova, I.V. (1992). Effect of spaceflight on natural killer cell activity. Journal of Applied Physiology. Vol.73, pp. 196S-200S

Sambadan, Y., Blanchard, J.J., Daughtridge, G., Kolb, R.J., Shanmugarajan, S., Pandruvada, S.N.M., Bateman, T.A. \& Reddy, S.V. (2010). Microarray profile of gene expression during osteoclast differentiation in modeled microgravity. Journal of Cellular Biochemistry. Vol.111, pp. 1179-1187Schneider, V. (1995). Bone and body mass changes during space flight. Acta Astronaut. Vol.36, pp. 463-6.

Schwarz, R.P., Goodwin, T.J. \& Wolf, D.A. (1992). Cell culture for three dimensional modeling in rotating-wall vessels: an application in microgravity. Journal of Tissue Culture Methods. Vol.14, No.2, pp. 51-58

Scott, J.M., Warburton, D.E., Williams, D., Whelan, S. \& Krassioukov, A. (2011). Spinal Cord. Vol.49, No.1, pp. 4-16

Semova, A., Semova, N., Lacelle, C., Marcotte, R., Petroulaski, E., Proestou, G. \& Wang, E. (2002). Alterations in TNF- and IL-related gene expression in space-flown WI38 human fibroblasts. FASEB Journal. Vol.16, No.8, pp. 899-901

Sheehan, K.B., McInnerney, K., Purevdorj-Gage, B., Altenburg, S.D. \& Hyman, L.E. (2007). Yeast genomic expression patterns in response to low-shear modeled microgravity. BMC Genomics. 8:3

Sheyn, D., Pelled, G., Netanely, D., Domany, E., Gazit, D. (2010) The effect of simulated microgravity on human mesenchymal stem cells cultured in an osteogenic differentiation system: a bioinformatics study. Tissue Engineering: Part A. Vol.16, No.11, pp. 3403-3412

Shi, L. (2006) Executive Summary: the MicroArray Quality Control (MAQC) Project, Food and Drug Administration, accessed July 8, 2011, available from: <http://www.fda.gov/downloads/ScienceResearch/BioinformaticsTools/Microar rayQualityControlProject/UCM132150.pdf >

Smith, S.M., Wastney, M.E., O'Brien, K.O., Morukov, B.V., Larina, I.M., Davis-Street, J.E., Oganov, V. \& Shackelford, L.C. (2005) Journal of Bone and Mineral Research. Vol.20, No.2, pp. 208-218

Sonnenfeld, G. (1999). Space flight, microgravity,stress, and immune responses. Advances in Space Research. Vol.23, pp. 1945-1953

Sonnenfeld, G. (2005). The immune system in space, including Earth-based benefits of spacebased research. Current Pharmaceutical Biotechnology. Vol.6, pp. 343-349 
Sonnenfeld, G., Gould, C.L., Williams, J. \& Mandel, A.D. (1988). Inhibited interferon production after space flight. Acta Microbiologica Hungarica. Vol.35, No.4, pp. 411-416.

Sonnenfeld, G. \& Shearer, W.T. (2002). Immune function during space flight. Nutrition. Vol.18, pp. 899-903.

Sonnenfeld, G. 2005. Use of animal models for space flight physiology studies, with special focus on the immune system. Gravitational Space Biology Bulletin. Vol.18, pp. 31-35

Stein, T.P. \& Schluter, M.D. (1994) Excretion of IL-6 by astronauts during spaceflight. American Journal of Physiology. Vol.266, No.3, pp. E448-E452

Stein, T.P., Schluter, M.D., Galante, A.T., Soteropoulus, P., Tolias, P.P., Grindeland, R.E., Moran, M.M., Wang, T.J., Polansky, M. \& Wade, C.E. (2002). Energy metabolism pathways in rat muscle under conditions of simulated microgravity. Journal of Nutritional Biochemistry. Vol.13, pp. 471-478

Stekel, D. (2003) Microarray Bioinformatics. Cambridge University Press, ISBN 0-521-52587-X, Cambridge, UK

Tan, P.K., Downey, T.J., Spitznagel, E.L., Xu, P., Fu, D., Dimitrov, D.S., Lempicki, R.A., Raaka, B.M. \& Cam, M.C. (2003). Evaluation of gene expression measurements from commercial microarray platforms. Nucleic Acids Research. Vol.31, No.19, pp. 5676-5684

Taylor, W.E., Bhasin, S., Lalani, R., Datta, A. \& Gonzalez-Cadavid, N.F. (2002). Alteration of gene expression profiles in skeletal muscle of rats exposed to microgravity during spaceflight. Journal of Gravitational Physiology. Vol.9, No.2, pp. 61-70

Tsao, Y.D., Goodwin, T.J., Wolf, D.A. \& Spaulding, G.F. (1992). Responses of gravity level variations on the NASA/JSC bioreactor system. Physiologist. Vol.35, No.1 Suppl., pp. S49-S50.

Thomason, D.B. \& Booth, F.W. (1990). Atrophy of the soleus muscle by hindlimb unweighting. Journal of Applied Physiology. Vol. 68, No.1, pp. 1-12

Trappe, S., Costill, D., Gallagher, P. Creer, A., Peters, J.R., Evans, H., Riley, D.A. \& Fitts, R.H. (2009). Exercise In Space: Human Skeletal Muscle After 6 Months Aboard The International Space Station. Journal of Applied Physiology. Vol39, No.4, pp. 463-471

Torday, J.S. (2003). Parathyroid hormone related protein is a gravisensor in lung and bone cell biology. Advances in Space Research. Vol32, pp. 1569-1576

Ullrich, O., Huber, K. \& Lang, K. (2008). Signal transduction in cells of the immune system in microgravity. Cell Communication and Signaling. 6:9

Valles, J.M. \& Guevorkain, K. (2002). Low gravity on earth by magnetic levitation of biological material. Journal of Gravitational Physiology. Vol.9, No.1, pp. p11-p14

van Loon, J.J.W.A. 2007. Some history and use of the random positioning machine, RPM, in gravity related research. Advances in Space Research. Vol.39, pp. 1161-1165

Vernikos, J. \& Schneider, V.S. (2010). Space, gravity, and the physiology of aging: parallel or convergent disciplines? A mini-review. Gerontology. Vol.56, No.2, pp. 157-166.

Vose, G.P. (1974). Review of roentgenographic bone demineralization studies of the Gemini space flights. American Journal of Roentgenology, Radium Therapy and Nuclear Medicine. Vol121, No.1, pp. 1-4

Walther, I., Pippia, P., Meloni, M.A., Turrini, F., Mannu, F. \& Cogoli, A. (1998). Simulated microgravity inhibits the genetic expression of interleukin-2 and its receptor in mitogen-activated T lymphocytes. FEBS Letters. Vol.436, No.1, pp. 115-118. 
Ward, N.E., Pellis, N.R., Risin, S.A. \& Risin, D. (2006). Gene Expression Alterations in Activated Human T-Cells Induced by Modeled Microgravity. Journal of Cellular Biochemistry. Vol.99, pp. 1187-1202.

Wilson, J.W., Ott, C.M., Ramamurthy, R., Porwollik, S., McClelland, M., Pierson, D.L. \& Nickerson, C.A. (2002a). Low-shear modeled microgravity alters the Salmonella enterica serovar typhimurium stress response in a RpoS-independent manner. Applied Environmental Microbiology. Vol.68, No.11, pp. 5408-16

Wilson, J.W., Ramamurthy, R., Porwollik, S., McCelland, M., Hammond, T., Allen, P., Ott, M.C., Pierson, D.L. \& Nickerson, C.A. (2002b). Microarray analysis identifies Salmonella genes belonging to the low-shear modeled microgravity regulon. Proceedings of the National Academy of Science USA. Vol.99, No.21, pp. 13807-13812

Wittwer, P., Fluck, M., Hoppeler, H., Muller, S., Desplanches, D. \& Billeter, R. (2002). Prolonged unloading of rat soleus muscle causes distinct adaptations of the gene profile. FASEB Journal. Vol.16, pp. 884-886

Wolber, P.K., Collins, P.J., Lucas, A.B., De Witte, A. \& Shannon, K.W. (2006). The Agilent in situ-synthesized microarray platform. Methods in Enzymology. Vol.410, pp. 28-57

Yamada, S., Ganno, T., Ohara, N. \& Hayashi, Y. (2007). Chitosan monomer accelerates alkaline phosphatase activity on human osteoblastic cells under hypofunctional conditions. Journal of Biomedical Materials Research Part A. Vol.83, pp. 290-295

Yu, Z.B., Zhang, L.F. \& Jin, J.P. (2001). A proteolytic NH2-terminal truncation of cardiac troponin I that is up-regulated in simulated microgravity. Journal of Biological Chemistry. Vol.276, No.19, pp. 15753-15760

Zhang, P, Hamamura, K. \& Yokota, H. (2008). A brief review of bone adaptation to unloading. Genomics, Proteomics, and Bioinformatics. Vol6, No.1, pp. 4-7

Zayzafoon, M., Gathings, W.E. \& McDonald, J.M. (2004). Modeled microgravity inhibits osteogenic differentiation of human mesenchymal stem cells and increases adipogenesis. Endocrinology. Vol.145, No.5, pp. 2421-2432 


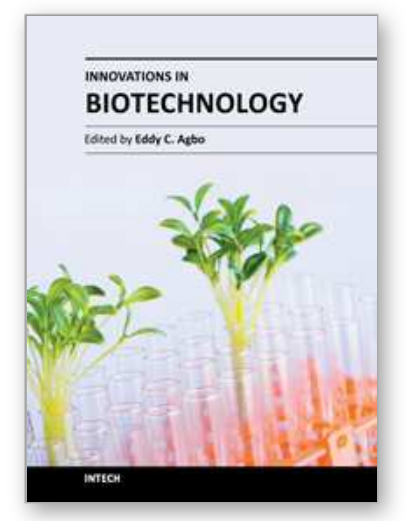

\author{
Innovations in Biotechnology \\ Edited by Dr. Eddy C. Agbo
}

ISBN 978-953-51-0096-6

Hard cover, 474 pages

Publisher InTech

Published online 17, February, 2012

Published in print edition February, 2012

Innovations in Biotechnology provides an authoritative crystallization of some of the evolving leading-edge biomedical research topics and developments in the field of biotechnology. It is aptly written to integrate emerging basic research topics with their biotechnology applications. It also challenges the reader to appreciate the role of biotechnology in society, addressing clear questions relating to biotech policy and ethics in the context of the research advances. In an era of interdisciplinary collaboration, the book serves an excellent indepth text for a broad range of readers ranging from social scientists to students, researchers and policy makers. Every topic weaves back to the same bottom line: how does this discovery impact society in a positive way?

\title{
How to reference
}

In order to correctly reference this scholarly work, feel free to copy and paste the following:

Jade Q. Clement (2012). Gene Expression Microarrays in Microgravity Research: Toward the Identification of Major Space Genes, Innovations in Biotechnology, Dr. Eddy C. Agbo (Ed.), ISBN: 978-953-51-0096-6, InTech, Available from: http://www.intechopen.com/books/innovations-in-biotechnology/gene-expression-microarraysin-microgravity-research-toward-the-identification-of-major-space-genes

\section{INTECH}

open science | open minds

\section{InTech Europe}

University Campus STeP Ri

Slavka Krautzeka 83/A

51000 Rijeka, Croatia

Phone: +385 (51) 770447

Fax: +385 (51) 686166

www.intechopen.com

\section{InTech China}

Unit 405, Office Block, Hotel Equatorial Shanghai

No.65, Yan An Road (West), Shanghai, 200040, China

中国上海市延安西路65号上海国际贵都大饭店办公楼 405 单元

Phone: +86-21-62489820

Fax: +86-21-62489821 
(C) 2012 The Author(s). Licensee IntechOpen. This is an open access article distributed under the terms of the Creative Commons Attribution 3.0 License, which permits unrestricted use, distribution, and reproduction in any medium, provided the original work is properly cited. 